Research Article

\title{
In the hearts and minds of employees: A model of pre-adoptive appraisal toward artificial intelligence in organizations
}

\author{
Yi-Te Chiu $^{\text {a }}$, Yu-Qian Zhu ${ }^{\text {b, } * \text {, Jacqueline Corbett }}{ }^{\mathrm{c}}$ \\ ${ }^{a}$ Wellington School of Business and Government, Victoria University of Wellington | Te Herenga Waka, New Zealand \\ ${ }^{\mathrm{b}}$ National Taiwan University of Science and Technology, Taiwan, ROC \\ ${ }^{\mathrm{c}}$ Université Laval, Quebec, Canada
}

\section{A R T I C L E I N F O}

\section{Keywords:}

Affective attitude

Artificial intelligence

Cognitive appraisal

Cognitive attitude

Employees

Pre-adoption

Subjective knowledge

Turnover

\begin{abstract}
A B S T R A C T
Organizations face increasing pressure to implement artificial intelligence (AI) within a variety of business processes and functions. Many perceived benefits surround AI, but a considerable amount of trepidation also exists because of the potential of AI to replace human employees and dehumanize work. Questions regarding the future of work in the age of AI are particularly salient in pre-adoption organizations, before employees have the opportunity to gain direct experience with AI. To cope with this potentially stressful situation, employees engage in cognitive appraisal processes based on their own knowledge and personal use of AI. These pre-adoptive appraisals of AI influence both affective and cognitive attitudes, which in turn trigger behavioral responses that influence an organization's ability to leverage AI successfully. Our survey of 363 Taiwanese employees shows that perceptions of AI's operational and cognitive capabilities are positively related to affective and cognitive attitudes toward AI, while concerns regarding AI have a negative relationship with affective attitude only. Interaction effects of employee knowledge and affective attitude are also observed. This work's main contribution lies in the development of an empirically-tested model of the potential impact of AI on organizations from an employee perspective in the pre-adoption phase. These results have practical implications for how organizations prepare for the arrival of this transformative technology.
\end{abstract}

\section{Introduction}

Touted as the most important general-purpose technology of this era (e.g., Brynjolfsson \& McAfee, 2017), AI is attracting substantial interest from organizations. AI represents the ability of a machine to learn from experience and adjust to new inputs in order to execute human-like tasks (Duan, Edwards, \& Dwivedi, 2019). In this way, AI has the ability to "augment and assist human capabilities by sensing and continuously learning, reasoning and inferring, deciding, and acting to drive a business outcome" (Teradata, 2017, p. 3).

Although $47 \%$ of organizations report having integrated at least one AI application into their business processes (Chui \& Malhotra, 2018), another half of organizations has not yet committed to specific implementations of AI, suggesting the adoption of enterprise AI applications is just starting to take hold (Mikalef, Pappas, Krogstie, Jaccheri, \& Rana, 2021; Tarafdar, Beath, \& Ross, 2019). A substantial proportion of large organizations, not to mention small and medium-sized enterprises, are still in the pre-adoption phase of the technology life cycle.
While enterprise AI has sparked interest and optimism in terms of improving future conditions such as enhanced decision support, stakeholder relationships, and innovations (Borges, Laurindo, Spínola, Gonçalves, \& Mattos, 2021), it has also raised concerns about the future of work due to issues around data privacy, the reduction of human value, ingrained biases, lack of transparency, and the replacement of human relationships with human-machine relationships (Levy, 2018; Müller \& Bostrom, 2016). Since AI's transformative effects influence employees' intention to stay with or leave the organization (Brougham \& Haar, 2018; Li, Bonn, \& Ye, 2019; Mahlasela \& Chinyamurindi, 2020)), organizations need to help their employees adapt to a AI-driven digital future (Wang et al., 2017).

The information systems (IS) research community has contributed to improving our understanding of how organizations grasp opportunities and address challenges in the face of transformative technologies like AI (Duan et al., 2019; Dwivedi et al., 2021). Extant research, situated primarily from an organizational perspective, has investigated success and risk factors (e.g., Pan, Froese, Liu, Hu, \& Ye, 2021; Sun \& Medaglia,

\footnotetext{
* Corresponding author.

E-mail address: yzhu@mail.ntust.edu.tw (Y.-Q. Zhu).
} 
2019), AI-driven strategies (e.g., Borges et al., 2021), value creation with AI (e.g., Papadopoulos, Baltas, \& Balta, 2020), and customers' perspectives on AI (Balakrishnan \& Dwivedi, 2021a, [Balakrishnan \& Dwivedi, 2021b]2021b; Gursoy, Chi, Lu, \& Nunkoo, 2019) . Employees' standpoints have received limited attention. A small amount of research has investigated perceived benefits and concerns and how these perceptions impact turnover intention (e.g., Abdullah \& Fakieh, 2020; Ardon \& Schmidt, 2020; Brougham \& Haar, 2018; Li et al., 2019). Research has also examined how attitudes are shaped by cognitive evaluations of AI (Abdullah \& Fakieh, 2020; Mahlasela \& Chinyamurindi, 2020) and affect behavioral intentions (Ardon \& Schmidt, 2020; Li et al., 2019).

To our knowledge, no studies have considered the nature of AI and the role of affective attitudes in employees' responses to AI. AI's distinctive learning, cognitive, and intelligent capabilities set it apart from traditional enterprise IT, such as ERP and cloud computing, and can evoke strong feelings and emotions (Brock \& von Wangenheim, 2019; Huang \& Rust, 2021). The current literature leaves unanswered questions, such as how employees' attitudes toward AI develop, how unique characteristics of AI influence attitudes, and what role cognition ('thinking') and affect ('feeling') play in influencing employees' behavioral intention.

Our aim with this research is to address some of these unanswered questions. To do so, we draw on the cognitive appraisal theory (Lazarus \& Folkman, 1984) to illuminate the process through which people evaluate and respond to challenging situations. The theory suggests that, depending on an individual's goal, coping capacity, and expectancy about the future, people perceive opportunities, harm/loss, threats, and challenges. With this appraisal comes positive or negative emotions. The context of interest in this study is employees' cognitive appraisal at the pre-adoption phase of $\mathrm{AI}$, the period during which organizations consider the need for a technology (Lai \& Mahapatra, 1997), but before a specific IT solution is implemented (Herold, Farmer, \& Mobley, 1995). Pre-adoptive appraisal is oriented to the future based on a limited set of cues. Factors suggested by contemporary IT adoption literature, such as performance expectancy, effort expectancy, and social influence for the use of a particular type of AI (Venkatesh, 2021; Vimalkumar, Sharma, Singh, \& Dwivedi, 2021), have limited applicability here. Rather, employees preconceive what $\mathrm{AI}$ is or will be able to achieve and how their work conditions may be affected by AI. Their evaluations lead to cognitive and affective attitudes, which in turn influence their behavioral intentions toward the technology and their organization.

In this context, two research questions guide our inquiries: during pre-adoptive appraisal, what factors contribute to employees' affective and cognitive attitudes toward AI, and how do these attitudes influence employees' behavioral responses? More specifically, this study examines the impacts of employees' coping capacity (i.e., subjective knowledge), employees' perceived capabilities of AI (including operational and cognitive capabilities), and anticipated outcomes of AI on affective and cognitive attitudes toward AI. We also test the relationship between attitudes and behavioral intentions toward AI (intention to use) and toward organizations (intention to leave). Intention to use indicates if the implementation of AI will be successful. Turnover intention has been highlighted as a major threat to organizations in prior research on $\mathrm{AI}$ adoption (Brougham \& Haar, 2018; Li et al., 2019; Mahlasela \& Chinyamurindi, 2020; Prentice, Dominique Lopes, \& Wang, 2020). Moreover, due to the media coverage on job displacement caused by AI, employees are more likely to consider intention to leave during cognitive appraisals. Both behavioral responses should be carefully considered by organizations in the pre-adoption stage. By revealing the relationships among these factors, we contribute to theory and practice in the following ways.

First, we offer an appraisal-based theory for IT to explain how and why employees demonstrate certain responses toward AI in the preadoption phase. Complementary to previous research focusing on influences of anticipated outcomes of $\mathrm{AI}$, such as job replacement
(Brougham \& Haar, 2018) and job monitoring (Brougham \& Haar, 2017), we discover differential impacts of AI cognitive and operational capabilities on attitudes. This insight highlights that the distinctive nature of AI can shape cognitive appraisal. Thus, organizations should engage with employees before introducing a specific type of AI.

Second, we present evidence for the need to balance cognitive and affective attitudes when studying technologies (Thompson, 2012). This study demonstrates that affective attitudes act as an intermediary between cognitive appraisal of AI and behavioral intention. Emotional experience is an integral part of coping (Lazarus \& Folkman, 1984) but has not been tested in the context of AI. Thus, the findings enrich context-specific theorizing in IS research (Hong et al., 2014). Contextualization improves the accuracy of models, makes interpretation of results more robust, and enhances the relevance of research (Hong, Chan, Thong, Chasalow, \& Dhillon, 2014; Johns, 2006).

Third, we enrich the cognitive appraisal theory, which focuses on emotional experiences derived from appraisals. By integrating cognitive attitudes in the model, we offer a better understanding of the potential for employees to hold conflicted attitudes (e.g., negative affective attitudes but positive affective attitudes) and how thinking and feeling can individually and collectively influence employees' behavioral intentions.

For practice, this study has important implications for organizations in pre-AI adoption. Attitudes has been considered as integral to understand behavior when facing IT innovations (Dwivedi, Rana, Jeyaraj, Clement, \& Williams, 2019). Previous research suggests that AI's transformative effects influence employees' intention to stay with the organization (Prentice et al., 2020). However, retaining skilled individuals who understand the organization to work with AI is essential (Wang et al., 2017), even as some of these employees' jobs may be automated, eliminated, or transformed through AI (Levy, 2018). Managerial decisions will need to be made during the pre-adoption phase, while employees' attitudes are still forming (Veiga, Keupp, Floyd, \& Kellermanns, 2014). Our results confirm that both affective and cognitive attitudes deserve mangers' attention before AI is introduced. Managers should carefully assess employees' knowledge about AI and their appraisals of AI's characteristics and consequences.

This article is structured as follows. In Section 2, we provide the conceptual background of the study and then develop the research model and hypotheses. In Section 3, we describe the methodology. This is followed by the presentation of results in Section 4. In Section 5, we discuss the implications of the findings, contributions, limitations, and directions for future research. Section 6 concludes the paper with some final thoughts.

\section{Theoretical foundations and research model}

\subsection{Cognitive appraisal theory}

Lazarus and Folkman's (1984) cognitive appraisal theory was developed to explain the coping process that takes place when a person faces a novel or challenging situation. When such a situation arises, an individual's initial appraisal is driven by two forces: the perception of the situation and the individual's knowledge, beliefs, values, and goals. This appraisal, which has both cognitive and affective aspects, then leads to different coping mechanisms manifest through attitudes and behavioral responses. Coping responses range from engagement to deviance (Bhattacherjee, Davis, Connolly, \& Hikmet, 2018). When facing a challenging situation of personal relevance, individuals who do not have resources to cope are most likely to view the situation as a potential threat or harm, which in turn arouses negative emotions, including fear, stress, and anxiety. People may avoid these stressful situations by distancing or withdrawing from technologies (Fadel \& Brown, 2010). On the other hand, people who have abundant knowledge and skills can evaluate the same situation as an opportunity and experience mainly positive emotions, such as happiness and excitement. 
Cognitive appraisal theory can help to explain coping responses in a diverse range of situations. In the IS discipline, this perspective has been used effectively to understand the adoption of new technologies, which can create disruptive and stressful situations for users. Current IS research using cognitive appraisal theory is situated primarily in the post-adoption phase of implementation. For example, in an 8-year investigation of a patient order system, Bhattacherjee et al. (2018) studied physicians' appraisals of the system in multiple phases of the project. Physicians appraised a specific type of technology, including opportunities, threats, and their control of the technology. High threats and low control led to resistance. In post-adoptive appraisals, the technology is specified and, therefore, users consider immediate impacts of the technology on work, such as perceived usefulness, effort expectancy, and perceived ease of use (Fadel \& Brown, 2010; Gursoy et al., 2019). Meanwhile, users also appraise if they have resources to cope with challenges. These resources may include individual knowledge and capability related to the technology (Rahman, Ko, Warren, \& Carpenter, 2016), organizational support, and the readiness of IT infrastructure (Bhattacherjee et al., 2018; Fadel \& Brown, 2010). Resulting from the appraisal of the technology, employees' reactions are centred around technology and may take the form of one of four different types of use: engaged, compliant, reluctant, and deviant (Bhattacherjee et al., 2018).

Although subject to less research attention, cognitive appraisal processes in the pre-adoption phase of technology have been found to differ from those in the post-adoption phase. Prior to the adoption of a technology, as organizations consider the need for IT and evaluate various options, potential users are not aware of what specific application or system will be introduced in the work environment. Thus, they can only appraise the technology in general. Moreover, employees may be uncertain about the personal resources they possess or the support available from peers and the organization to deal with the technological change. In these cases, employees may avoid stressful situations by distancing or withdrawing from technologies (Fadel \& Brown, 2010). In the extreme form, if the impacts of changes are expected to be far-reaching, employees will opt for other work environments (Armstrong-Stassen, 1994). Table 1 summarizes the differences between the pre-adoptive appraisal and post-adoptive appraisal for IT.

\subsection{Employee coping with enterprise AI adoption}

Given the nascent stage of AI adoption and recognizing that employees' appraisals in the pre-adoptive phase can influence behavioral responses to technology, we focus on the pre-adoptive cognitive appraisal of AI. In this phase, AI allows employees to envision productivity gains from decision support, customer and employee engagement, automation, and the creation of new products (Borges et al., 2021). However, there have been concerns raised regarding AI's general capabilities (Abdullah \& Fakieh, 2020; Mahlasela \& Chinyamurindi, 2020) and the potential implications (Ardon \& Schmidt, 2020) on people and organizations. Beliefs in positive impacts brought by $\mathrm{AI}$ evoke positive

Table 1

Comparison between Pre-adoptive Appraisal and Post-adoptive Appraisal.

\begin{tabular}{|c|c|c|}
\hline Dimension & Pre-adoptive Appraisal & Post-adoptive appraisal \\
\hline Object & $\begin{array}{l}\text { General IT (e.g., artificial } \\
\text { intelligence) }\end{array}$ & $\begin{array}{l}\text { A specific type or application of } \\
\text { IT (e.g., service robots) }\end{array}$ \\
\hline Appraisal & $\begin{array}{l}\text { Consideration of general } \\
\text { capabilities of the IT, perceptions } \\
\text { of the technologies' potential } \\
\text { impacts, general experience and } \\
\text { knowledge of IT }\end{array}$ & $\begin{array}{l}\text { Appraisal based on the use of IT, } \\
\text { including its performance and } \\
\text { effort expectancy, Direct } \\
\text { experience and information } \\
\text { regarding organizational support, } \\
\text { technical support, peer support }\end{array}$ \\
\hline Responses & $\begin{array}{l}\text { Preconceived attitude toward IT, } \\
\text { such as intention to use, and } \\
\text { attitude toward the work } \\
\text { environment, such as intention } \\
\text { to leave }\end{array}$ & $\begin{array}{l}\text { Behavioral responses to the IT } \\
\text { application or system, such as use } \\
\text { or resistance }\end{array}$ \\
\hline
\end{tabular}

affective attitudes (Gursoy et al., 2019), while the perception of threats caused by AI creates negative cognitive and affective attitudes (Brougham \& Haar, 2018). Negative attitudes can be exacerbated when employees do not believe that they have sufficient resources, such as knowledge about AI, to alleviate or eliminate stressful situations (Abdullah \& Fakieh, 2020).

Negative appraisals can have serious impacts on organizations. Brougham and Haar (2018) found that, across diverse industries and job positions in New Zealand, concerns about job loss caused by AI and robotics not only diminished employees' organizational commitment and career satisfaction, but also increased turnover intentions, cynicism, and depression. Similarly, Li et al. (2019) reported that hotel employees in China who anticipated their jobs to be replaced by AI showed higher turnover intentions. This relationship was weakened by perceived organizational support and strengthened by a competitive psychological climate. The fear and concerns of AI taking away jobs are shared in other industries as well, including both the private sector and the public sector (Mahlasela \& Chinyamurindi, 2020). Two separate studies, one from Saudi Arabia and one from the U.S., reported similar findings over job security concerns in the healthcare industry (Abdullah \& Fakieh, 2020; Ardon \& Schmidt, 2020).

Table 2 summarizes the most relevant research related to employees' pre-adoptive appraisal of AI. Although still developing, this literature highlights the importance of users' appraisals on individual and organizational outcomes. Previous work has investigated either AI in general or anticipated impacts of $\mathrm{AI}$, but has not directly addressed the relationship between these two factors. Also, it remains unclear what specific AI capabilities spark different responses. Furthermore, when considering appraisals of AI, previous studies mainly assess cognitive attitudes and overlook affective attitudes. As a result, we have an incomplete understanding of the role of cognitive and affective attitudes during the appraisal process. We aim to fill this knowledge gap by developing and testing a theory explaining how employees' preadoptive appraisals of AI influence cognitive and affective attitudes and employees' behavioral responses to this technology.

\subsection{Research model and hypotheses}

The appraisal-based research model for this study comprises three main parts: (1) factors involved in employees' pre-adoptive appraisal of AI, (2) affective and cognitive attitudes, and (3) employees' behavioral responses. The model is illustrated in Fig. 1.

\subsubsection{Influence of appraisal on affective and cognitive attitudes}

As discussed, an individual's initial appraisal results from the resources they have available combined with their perceptions of the technology. With respect to the former, we investigate employee knowledge of AI because the knowledge people have regarding an innovation influences their attitudes and subsequent decisions of whether to adopt or reject an innovation (Rogers, 2003). Knowledge influences individuals' information searching and processing (Klerck \& Sweeney, 2007) and, because new knowledge can change people's beliefs, it also influences their attitudes and behaviors regarding a new product, service or technology (Aertsens, Mondelaers, Verbeke, Buysse, \& Van Huylenbroeck, 2011).

Two main dimensions of knowledge are objective knowledge, which is what a person actually knows about a product or technology, and subjective knowledge, which is a person's perception of what they know (Brucks, 1985). Objective and subjective knowledge are moderately correlated (Carlson, Vincent, Hardesty, \& Bearden, 2008) as what people know and what they think they know often diverge. Differences are most likely to arise when the subject of the knowledge is difficult to communicate, such as complex scientific information (Klerck \& Sweeney, 2007). In these situations, people may believe they know more about the particular subject than they actually do, or inversely, lack confidence in what they actually do know. Knowledge plays an essential 
Table 2

Research on Employees' Pre-adoptive Appraisal of AI.

\begin{tabular}{|c|c|c|c|}
\hline Research & $\begin{array}{l}\text { Method and } \\
\text { Context }\end{array}$ & $\begin{array}{l}\text { Pre-adoptive } \\
\text { Appraisal of AI }\end{array}$ & Findings \\
\hline $\begin{array}{r}\text { Brougham and } \\
\text { Haar (2018) }\end{array}$ & $\begin{array}{l}\text { Survey, } 120 \\
\text { employees from } \\
\text { various } \\
\text { industries in } \\
\text { New Zealand }\end{array}$ & $\begin{array}{l}\text { Emotions related } \\
\text { to the perception } \\
\text { of the impacts } \\
\text { brought by AI } \\
\text { (perceived } \\
\text { threats) }\end{array}$ & $\begin{array}{l}\text { Greater STARA } \\
\text { (Smart Technology, } \\
\text { Artificial } \\
\text { Intelligence, } \\
\text { Robotics, and } \\
\text { Algorithms) } \\
\text { awareness (the } \\
\text { extent to which } \\
\text { employees feel their } \\
\text { job could be replaced } \\
\text { by AI and robotics, } \\
\text { focusing on feelings) } \\
\text { is negatively related } \\
\text { to organizational } \\
\text { commitment and } \\
\text { career satisfaction, } \\
\text { and positively } \\
\text { related to turnover } \\
\text { intentions, cynicism, } \\
\text { and depression. }\end{array}$ \\
\hline Li et al. (2019) & $\begin{array}{l}\text { Survey, } 468 \text { full- } \\
\text { time five-star } \\
\text { hotel employees } \\
\text { in China }\end{array}$ & $\begin{array}{l}\text { Cognitive } \\
\text { evaluation of AI } \\
\text { concerning its } \\
\text { risks }\end{array}$ & $\begin{array}{l}\text { AI and robotics } \\
\text { awareness is } \\
\text { positively associated } \\
\text { with employee } \\
\text { turnover intention. } \\
\text { This relationship is } \\
\text { moderated by } \\
\text { perceived } \\
\text { organizational } \\
\text { support and } \\
\text { competitive } \\
\text { psychological } \\
\text { climate. }\end{array}$ \\
\hline $\begin{array}{l}\text { Abdullah and } \\
\text { Fakieh (2020) }\end{array}$ & $\begin{array}{l}\text { Survey, } 250 \\
\text { medical } \\
\text { employees in } \\
\text { Saudi Arabia }\end{array}$ & $\begin{array}{l}\text { Cognitive } \\
\text { evaluation of AI } \\
\text { concerning its } \\
\text { capabilities }\end{array}$ & $\begin{array}{l}\text { Employees fear that } \\
\text { AI will replace } \\
\text { employees and have } \\
\text { a general lack of } \\
\text { knowledge regarding } \\
\text { AI. Most employees } \\
\text { are unaware of the } \\
\text { advantages and most } \\
\text { common challenges } \\
\text { to AI applications in } \\
\text { the health sector. }\end{array}$ \\
\hline $\begin{array}{l}\text { Ardon and } \\
\text { Schmidt } \\
(2020)\end{array}$ & $\begin{array}{l}\text { Survey, } 1721 \\
\text { laboratory } \\
\text { employees in the } \\
\text { U.S. }\end{array}$ & $\begin{array}{l}\text { Cognitive } \\
\text { evaluation of AI } \\
\text { concerning its } \\
\text { impacts }\end{array}$ & $\begin{array}{l}\text { Laboratory } \\
\text { employees have } \\
\text { concerns regarding } \\
\text { job security and the } \\
\text { quality of AI } \\
\text { performance. } \\
\text { Meanwhile, they see } \\
\text { the potential for AI } \\
\text { and generally } \\
\text { support the adoption } \\
\text { of AI tools. }\end{array}$ \\
\hline $\begin{array}{l}\text { Mahlasela and } \\
\text { Chinyamurindi } \\
\text { (2020) }\end{array}$ & $\begin{array}{l}\text { Survey, } 186 \\
\text { government } \\
\text { employees in } \\
\text { South Africa }\end{array}$ & $\begin{array}{l}\text { Cognitive } \\
\text { evaluation of AI's } \\
\text { capabilities }\end{array}$ & $\begin{array}{l}\text { Employees' concerns } \\
\text { about increased job } \\
\text { overload and job } \\
\text { monitoring by AI } \\
\text { result in higher } \\
\text { intention to leave. }\end{array}$ \\
\hline
\end{tabular}

role in the cognitive appraisal process. Consistent with research showing that a lack of knowledge about AI can lead to a negative appraisal of AI (Abdullah \& Fakieh, 2020), we posit the overall effect of employee knowledge on both affective and cognitive attitudes will be positive.

In terms of affective attitude, knowledge about a particular subject can lead to more positive feelings and favorable emotions. The sustainability literature, for instance, has shown that environmental knowledge can lead to enhanced affective attachment to a particular location (Kim, Kim, \& Thapa, 2018) and, in the health care field, knowledge about AIDS/HIV can reduce nurses' fear and stigmatization of people living with the disease (Pisal et al., 2007). It is plausible that the more people know about AI, the more they will be concerned about it, leading to negative affective attitudes. However, based on cognitive appraisal theory, we argue that employees with a good knowledge of AI are likely to have more positive feelings (e.g., optimism) because knowledge provides an important capacity for coping. Conversely, employees with low knowledge have fewer coping resources and are likely to place more weight on media reports related to AI (Klerck \& Sweeney, 2007), rather than making their own assessments. Again, while low knowledge individuals may develop more positive affective attitudes toward AI if they rely on optimistic media reports, research suggests that subjective knowledge gained through biased media reports can lead to higher perceptions of risk (Klerck \& Sweeney, 2007). With a more limited ability to critically evaluate such information, employees may not be able to differentiate what is fictional from what is real, leading them to hold less positive or more negative affective attitudes (e.g., fear) toward AI. Thus, we hypothesize:

H1a. Employee knowledge of AI is positively associated with affective attitude toward AI.

From a cognitive perspective, the more employees know about AI, especially its limitations and application scope, the more they will be able to process diverse information to develop realistic expectations regarding the technology. In this respect, knowledge represents a valuable resource employees can draw upon during the cognitive appraisal process (Lazarus \& Folkman, 1984). When facing potential negative consequences arising from the technology, those with higher levels of knowledge with respect to the current state of AI development and the underlying technologies, will be able to identify ways in which such risks could be reduced or overcome. Thus, we hypothesize:

H1 b. Employee knowledge of AI is positively associated with cognitive attitude toward AI.

In addition to available resources, perceptions of a technology are also factored into an individual's appraisal. In our model, we consider the operational and cognitive capabilities of AI that aid in solving business problems (Chui \& Malhotra, 2018) and the perceived adverse affects of the technology.

Operational capabilities relate to the ability of AI to execute tasks reliability in a flexible manner and to integrate with other systems. By embedding algorithms into business processes, organizations use AI to enhance operations, making them more efficient, accurate, relevant, and reliable (Tarafdar, Beath, \& Ross, 2017). AI applications can automate repetitive and formulaic tasks and provide substantial improvements in the speed, reliability, and accuracy of data analysis and outcomes (Tarafdar et al., 2019). Operationally, enterprise AI applications offer two distinct advantages. First, AI has the ability to process increasingly large data sets, providing optimized solutions to support decision making (Hoon, 2019; Kim \& Kang, 2016) and, second, AI is able to automate routine tasks that previously required human intervention (Acemoglu \& Restrepo, 2018; Levy, 2018). During the cognitive appraisal process, when employees perceive operational benefits of AI, both positive cognitions and emotions can be induced (Choi, Sung, Lee, \& Cho, 2011). Perceptions of strong operational capacities of AI can trigger positive affective attitudes, such as confidence, excitement and trust. Employees may also have positive feelings toward AI due to the potential for reducing repetitive and dull work tasks [reference anonymized for review], as well as having access to innovative tools that allow for more informed decisions. Thus, we hypothesize:

H2a. Perceived operational capabilities of AI are positively associated with affective attitude toward AI.

At a cognitive level, employees are likely to perceive operational capabilities as being beneficial to their job and the organization by reducing costs and improving organizational performance. In the manufacturing sector, for instance, machine automation enabled with AI 


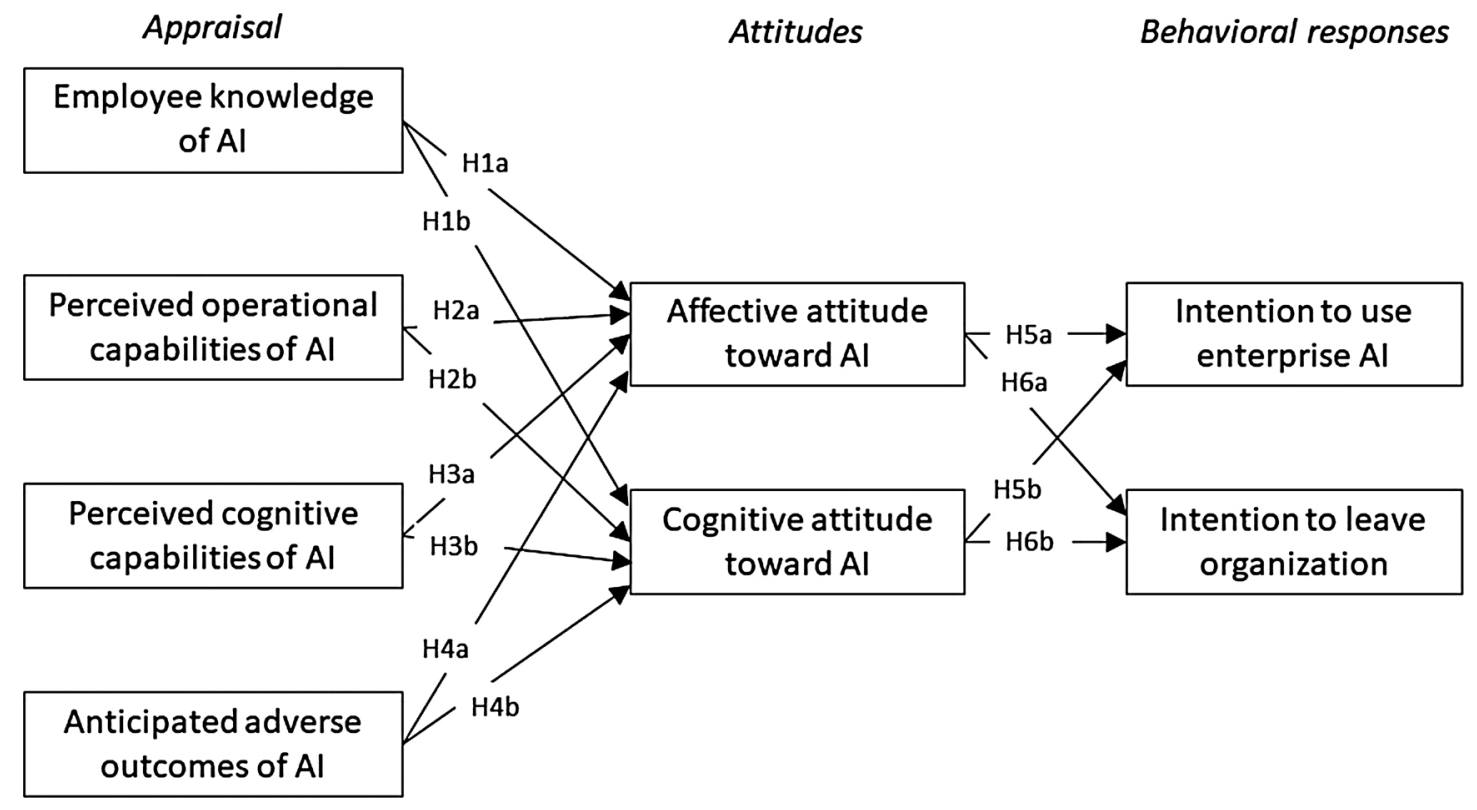

Fig. 1. Research Model: Pre-adoptive Appraisal toward Artificial Intelligence.

is expected to allow organizations to produce higher quality products faster and more efficiently. In addition, data gathered from these processes can help to inform operational decisions with the benefits of more accurate demand forecasting, preventative maintenance, optimized manufacturing processes and better materials procurement (Jimenez, 2018). Companies in the service industries are also expected to benefit from AI. According to consulting firm Accenture, the financial sector could realize $\$ 140$ billion in productivity and cost savings as AI becomes integrated into key activities of portfolio management, loan underwriting, and developing personalized services (Fuscaldo, 2019). When employees are exposed to these types of reports, they are likely to develop more positive cognitive attitudes toward AI in their own organization. Thus, we hypothesize:

H2b. Perceived operational capabilities of AI are positively associated with cognitive attitude toward AI.

Cognitive capabilities relate to the ability of AI to understand human language, understand context, and provide transparency into how the recommendations and decisions are made. These cognitive capabilities set AI apart from other enterprise systems, making them a highly valued general-purpose technology (Brynjolfsson \& McAfee, 2017). We posit that employees will develop more positive affective and cognitive attitudes when they perceive AI as having higher cognitive capabilities.

There is an inherent complexity in simulating human conversations as people have diverse ways of communicating (Griol, Molina, \& Callejas, 2014). Natural language understanding (NLU) occurs when the program aims at simulating the human being's understanding capabilities: the programs developed can then claim some cognitive validity (Sabah, 2010). A typical NLU problem may be stated as follows: "given an utterance $\mathrm{x}$ in a context c, output the desired action y" (Liang, 2016, p. 70). This example highlights the three main challenges: understanding the meaning of the utterance, understanding the context of the utterance, and then deciding how to respond (logical reasoning) (Srinivasan, 2016). As these challenges illustrate, human communication is not simply a matter of words, but also non-verbal cues (D'Mello, Graesser, \& King, 2010) and cognitive processes that lead to understanding the human interaction. Thus, AI must also be able to understand context.

One of the most common experiences people have with communicating with machines is through interactive voice response systems (IVR) that have become commonplace in customer service call centres.
Despite the operational efficiency that can be attained through these systems, people often report dislike, frustration and confusion when using them (Ellway, 2016). We argue that the same is likely to apply with AI applications. When employees perceive AI as being able to recognize and respond to natural human communications, they will form more positive emotional attitudes. They will expect to experience a more pleasurable and less frustrating experience (D'Mello et al., 2010) when interacting with an intelligent machine. Thus, we hypothesize:

H3a. Perceived cognitive capabilities of AI are positively associated with affective attitude toward AI.

Perceived cognitive capabilities are also likely to influence employees' cognitive attitudes. If $\mathrm{AI}$ is able to recognize and respond to natural human communications, people will believe that interacting with AI is more efficient (D'Mello et al., 2010). AI-based context-aware systems also demonstrate more ease in obtaining suitable data from the user and allows for a higher success rate in the human-machine interaction because it reduces the time required of the AI application to return relevant information back to the user (Griol et al., 2014). As a result, actions that might discourage use (e.g., re-requests of information) are reduced, and the quality of the interaction between the user and the AI application is increased (Griol et al., 2014). The third dimension of AI cognitive capabilities is the traceability and interpretability of the reasoning used to reach a conclusion (Brynjolfsson \& McAfee, 2017; Mittelstadt, Russell, \& Wachter, 2019). For many AI applications, interpretability and trust will be essential for adoption (Matthews, Lin, Panganiban, \& Long, 2019), particularly in mission-critical applications where people are held accountable (e.g., medicine, business) for the outcomes of the decisions. When this trust is low, employees may have less favorable cognitive attitudes toward AI, but when trust is high, they are likely to have more positive attitudes. Based on these arguments, we hypothesize:

H3b. Perceived cognitive capabilities of AI are positively associated with cognitive attitude toward AI.

Events characterized by novelty, personal relevance, and salience are likely to receive attention because of high accessibility in memory. Given the amount of coverage of AI in the public media and management literature, employees in pre-adoption organizations are evaluating an event that is likely to occur and proactively identifying futureoriented coping strategies (Aspinwall, 2005; Schwarzer \& Knoll, 
2003). In pre-adoptive appraisals, people evaluate potential consequences that involve psychological significance (Howe \& Krosnick, 2017).

When considering a new technology, employees tend to consider a range of outcomes, from immediate job-related outcomes (Ardon \& Schmidt, 2020; Brougham \& Haar, 2018; Li et al., 2019) to distant outcomes, such as the future of work and humanity (Gupta, Fischer, \& Frewer, 2012). Emergent technologies bring changes in job content and job security (Beaudry \& Pinsonneault, 2005; Lapointe \& Rivard, 2017). As discussed previously, AI excels at reliability and accuracy and can easily replace repetitive tasks. In complex problem domains, AI demonstrates the cognitive capabilities to provide knowledge and recommendations to humans. Some employees perceive benefits of AI, such as boosting productivity and releasing them from tedious or dangerous tasks, while others fear that the potential for AI to outsmart humans (Knickrehm, 2018). Both pundits (Müller \& Bostrom, 2016) and the public (Fast \& Horvitz, 2017) consider job change as the top anticipated outcome of AI. Anticipated impacts on society is a significant factor influencing the acceptance of controversial and transformative technology, such as nuclear power, biotechnology, and nanotechnology (Gupta et al., 2012). AI has the power to completely transform organizational and social contexts - shaping new ways of working, the value of the human, power structures, and economic systems. Some people anticipate that potential failures of AI could lead to dystopian outcomes (e.g., Bohannon, 2015) while others perceive AI to augment human's cognitive and physical capabilities (Nowak, Lukowicz, \& Horodecki, 2018).

The cognitive appraisal theory suggests that when people perceive threats, feelings are aroused (Lazarus \& Folkman, 1984). The risk-as-feelings hypothesis further adds that anticipated risky situations in the future can evoke immediate visceral reactions (Loewenstein, Weber, Hsee, \& Welch, 2001). As such, we hypothesize:

H4a. Anticipated adverse outcomes of AI are negatively associated with affective attitude toward AI.

Appraisal of consequences that AI will bring to job and society can also impact one's positive beliefs in AI because it brings new cognitive information, thereby influencing attitude formation (Edwards, 1990). For example, employees' cognitive attitudes for electronic health records systems were improved after perceiving positive impacts of the system on their job and the society (Angst \& Agarwal, 2009). As such, we hypothesize:

H4b. Anticipated adverse outcomes of AI are negatively associated with cognitive attitude toward AI.

\subsubsection{Behavioral outcomes resulting from attitudes}

In theory, attitude directs a person's attention and influences information processing and behaviors. However, empirical research presents variability in the degree to which attitudes predict behaviors. In Legris, Ingham, and Collerette's (2003) literature review, seven studies find a positive relationship between attitudes and behavioral intention, while four studies found no significant relationship. Among six meta-analysis studies (i.e., Dwivedi et al., 2019; Ritter, 2017; Schepers \& Wetzels, 2007; Scherer, Siddiq, \& Tondeur, 2019; ŠUmak, HeričKo, \& PušNik, 2011; Zhang, Zhu, \& Liu, 2012), the effect size between attitudes and behavioral intention ranges from $0.10(\mathrm{p}<0.01)$ (Dwivedi et al., 2019) to 0.61 ( $\mathrm{p}<.05)$ (Ritter, 2017). Such inconsistent results suggest there is a potential confounding factor influencing the relationship.

A primary focus on affective attitudes in IT research can account for some of variances (Kroenung \& Bernius, 2012). Yang and Yoo (2004) found cognitive attitudes, instead of affective attitudes, have strong effects on intention to use. Type of systems can also play a role in the relationship. The effect is stronger when the purpose of the system is aligned with the type of attitude. That is, the utilitarian system strengthens the relationship between cognitive attitudes and intention to use whereas the hedonic system amplifies the relationship between affective attitudes and intention to use (Kroenung \& Bernius, 2012; Van der Heijden, 2004). While not directly evaluating cognitive and affective attitudes, Wu and $\mathrm{Lu}$ (2013) found that extrinsic motivation requiring cognitive processing has higher predictive power for behavioral intention in the context of utilitarian systems, whereas intrinsic motivation that arouses emotion explains more variances in the adoption of hedonic systems.

AI, equipped with cognitive intelligence and social characteristics (Matthews et al., 2019), can be instrumental and engage users. Cognitive processing and affect arousal are both activated in the context of dual-purposed systems (Wu \& Lu, 2013). Considering the dual nature of AI, both affective attitudes and cognitive attitudes can be shaped.

Anticipation of IT during early appraisals come with emotions. A deterrence emotion, such as anxiety, can prevent users from adopting technologies whereas an achievement emotion, such as happiness and hope, increases intention to use (Beaudry \& Pinsonneault, 2010; Ding, 2018). When employees hold positive feelings toward AI due to human-like intelligence (Huang, Rust, \& Maksimovic, 2019) and perceived benefits over risks, they are motivated and committed to work with AI (Huang et al., 2019). As such, we hypothesize:

H5a. Affective attitude toward AI is positively associated with intention to use enterprise AI.

Previous research has shown a positive relationship between cognitive attitudes and intention to use (Dwivedi et al., 2019; Kroenung \& Bernius, 2012; Yang \& Yoo, 2004). Cognitive attitude toward AI is a summative evaluation of AI's capabilities. Positive cognitive attitudes denote higher anticipation of AI's benefits and value and are likely to enhance employees' intention to engage in AI. Therefore, we posit:

H5b. Cognitive attitude toward AI is positively associated with intention to use enterprise AI.

Job fears relating to the introduction of new technology leads to reduced organizational commitment and job satisfaction and increased depression and cynicism (Brougham \& Haar, 2018). AI is no exception as it weaves new patterns of working, adding meaningfulness to the job role while increasing anxiety (Nach \& Lejeune, 2010; Walsham, 1998). Leaving organizations is an extreme form of coping stressful situations (Armstrong-Stassen, 1994). However, the thought of leaving can develop in the pre-adoption phase as employees explore other types of jobs or jobs in other organizations where the perceived threat is lower. Intention to leave can escalate when negative affective attitudes accumulate. Thus, we hypothesize:

H6a. Affective attitude toward AI is negatively associated with intention to leave the organization.

Employees' negative cognitive attitudes toward AI suggest challenges and harms caused by AI. For instance, perpetual monitoring of AI alters the employee-employer relationship and reduces the employees' trust of their organization (Hirsch, 2019). Also, employees may doubt their ability to work with the technology, lose self-esteem, and worry about losing stature in their social and professional groups (Craig, Thatcher, \& Grover, 2019). Pre-emptive decisions by employees to leave the organization are therefore likely to occur, especially when employees anticipate that they are incompatible to AI-powered organizations in the future due to value incongruence or a lack of ability. Thus, we hypothesize:

H6b. Cognitive attitude toward AI is negatively associated with intention to leave the organization.

\section{Methodology}

To validate the proposed research model, we employed a survey research design applied to a sample of employees in pre-adoption 
organizations.

\subsection{Data collection}

We collected data via a market research firm in Taiwan with over 200,000 active members. Market research firms facilitate the data collection process for researchers by providing access to a representative sample of the target population while also ensuring the quality of responses. In February 2019, email invitations were sent out to randomly selected members of the firm. Respondents passing the initial qualification screening were directed to the on-line questionnaire. The screening required that respondents be currently employed at an organization contemplating AI applications in the future. Respondents were compensated with survey points by the market research firm that could be redeemed for a nominal cash value. We explained this research was about employees' responses to possible AI implementation in their organization. Respondents were instructed to fill out a questionnaire that included demographic information and items related to the constructs of interest (see Appendix). The market research firm was responsible for collecting an adequate number of good quality and complete surveys. The implemented survey included quality and logical checks to help ensure the respondents were reading and responding thoughtfully to each question. A total of 363 complete and usable surveys were received from the market research firm. As summarized in Table 3, the sample comprised $55 \%$ female respondents with the majority of respondents aged from 30 to 39 years. Employees were from companies operating in a diversity of industries and those in non-managerial jobs comprised more than $80 \%$ of the sample.

\subsection{Measures of constructs}

Items were adapted from the literature where available and appropriate. All the measures in the survey instrument used five-point Likert scales, with 1 indicating 'strongly disagree' and 5 indicating 'strongly agree', except as noted.

For employee knowledge, we chose to measure employees' subjective knowledge using five items adapted from Flynn and Goldsmith (1999). Practically, subjective knowledge is easier to measure than objective knowledge (Carlson et al., 2008). Moreover, subjective knowledge is positively related to individual's confidence in their knowledge and attitudes toward a product or service. This relationship maybe even stronger than the link between objective knowledge and attitudes and behaviors (Aertsens et al., 2011).

Perceived cognitive and operational capabilities of AI were both operationalized as second-order constructs made up of three dimensions. Perceived operational capabilities was made up of reliability (3 items), flexibility (3 items), and integration (3 items) adapted from

Table 3

Sample characteristics $(\mathrm{n}=363)$.

\begin{tabular}{llll}
\hline Characteristic & Group & Number & Percent of sample \\
\hline \multirow{2}{*}{ Gender } & Male & 163 & $44.9 \%$ \\
& Female & 200 & $55.1 \%$ \\
Age & $20-29$ & 58 & $16 \%$ \\
& $30-39$ & 181 & $49.9 \%$ \\
& $40-49$ & 96 & $26.4 \%$ \\
& 50 and above & 28 & $7.7 \%$ \\
Industry & Service & 112 & $30.9 \%$ \\
& Manufacturing & 97 & $26.7 \%$ \\
& Agriculture & 2 & $1.4 \%$ \\
& Information tech & 39 & $10.7 \%$ \\
& Finance & 16 & $4.4 \%$ \\
Position & Government & 40 & $11 \%$ \\
& Freelance & 14 & $3.9 \%$ \\
& Others & 40 & $11.1 \%$ \\
& Management & 70 & $19.3 \%$ \\
& Non-management & 293 & $80.7 \%$ \\
\hline
\end{tabular}

Nelson, Todd, and Wixom (2005) for the AI context. Perceived cognitive capabilities of AI was made up of natural language processing (3 items), understanding context ( 3 items), and logic transparency ( 3 items). The nine items were self-developed based on Srinivasan (2016).

Anticipated adverse outcomes was made up of two dimensions: jobrelated outcomes were measured using three items, and humanityrelated outcomes were measured with three items. These six items were adapted from ARM and Northstar (2018) and Jiang, Muhanna, and Klein (2000) respectively.

Affective and cognitive attitudes were measured using three items, each adapted from Yang and Yoo (2004). For these items, a five-point Likert scale was used anchored at each end with 5 being positive (e.g., happy) and 1 being negative (e.g., annoyed) attitudes.

With respect to the dependent variables, intentions to use enterprise AI was measured with three items adapted from Teo (2011). Intention to leave the organization was measured with four items adapted from Shore and Martin (1989).

Table 4 below summarized the measurements of the constructs used in this research.

\section{Analyses and results}

\subsection{Measurement model testing}

We performed Partial Least Squares (PLS) analysis with SmartPLS 2.0.M3 to test our model. PLS, a variance-based structural equation modelling method, can accommodate both reflective and formative measures in analysis. PLS aims to maximize the explained variance in the dependent variables and is better suited for exploratory research than covariance-based structural equation modeling (Hulland, Ryan, \& Rayner, 2010). It has been widely used in IS as it works well with small sample sizes, formative measures, and non-normal data, and its focus on prediction, theory building and flexibility with complex models (Ringle, Sarstedt, \& Straub, 2012). Because our model consists of formative constructs and the main goal is to develop a comprehensive theoretical framework to understand how employees appraise and respond to AI, PLS is the appropriate method to assess our model.

For the measurement model, we conducted a confirmatory factor analysis to assess the reliability and validity of our constructs. The results are summarized in Table 5 .

All the proposed constructs achieved acceptable to excellent reliability, evidenced by their Cronbach's $\alpha$ values and composite reliability scores. The average variance extracted (AVE) values for each construct exceeded 0.5 (Fornell \& Larcker, 1981). For discriminant validity, two criteria were examined. First, the square root of AVE is greater than inter-construct correlations to other factors as shown in Table 6. Second, the cross-loadings of each item were examined. The loading of each item on its designated construct was higher than any other construct (see Appendix for the loading and cross-loading table).

We ran Harman's one-factor test to estimate whether common method bias was an issue in our data (Podsakoff, MacKenzie, \& Podsakoff, 2012). An unrotated principal components factor analysis was conducted with all items. Eleven factors with eigenvalue greater than 1.0 emerged, with the first factor explaining $26.74 \%$ of the total variance, suggesting that common method variance is unlikely to confound the interpretations of the results. Multicollinearity was assessed via tolerances and variance inflation factor (VIF) of the independent constructs. VIF lower than 5 and tolerance values higher than 0.1 are suggested values to exclude multicollinearity concerns (Mansfield \& Helms, 1982). As Table shows, the VIF values are all well below 5, with the tolerance values greater than 0.1 , implying that multicollinearity is not an issue with the data. (Table 7)

\subsection{Structural model testing}

We analyzed the full model for hypothesis testing with SmartPLS. 
Table 4

Measurements of constructs.

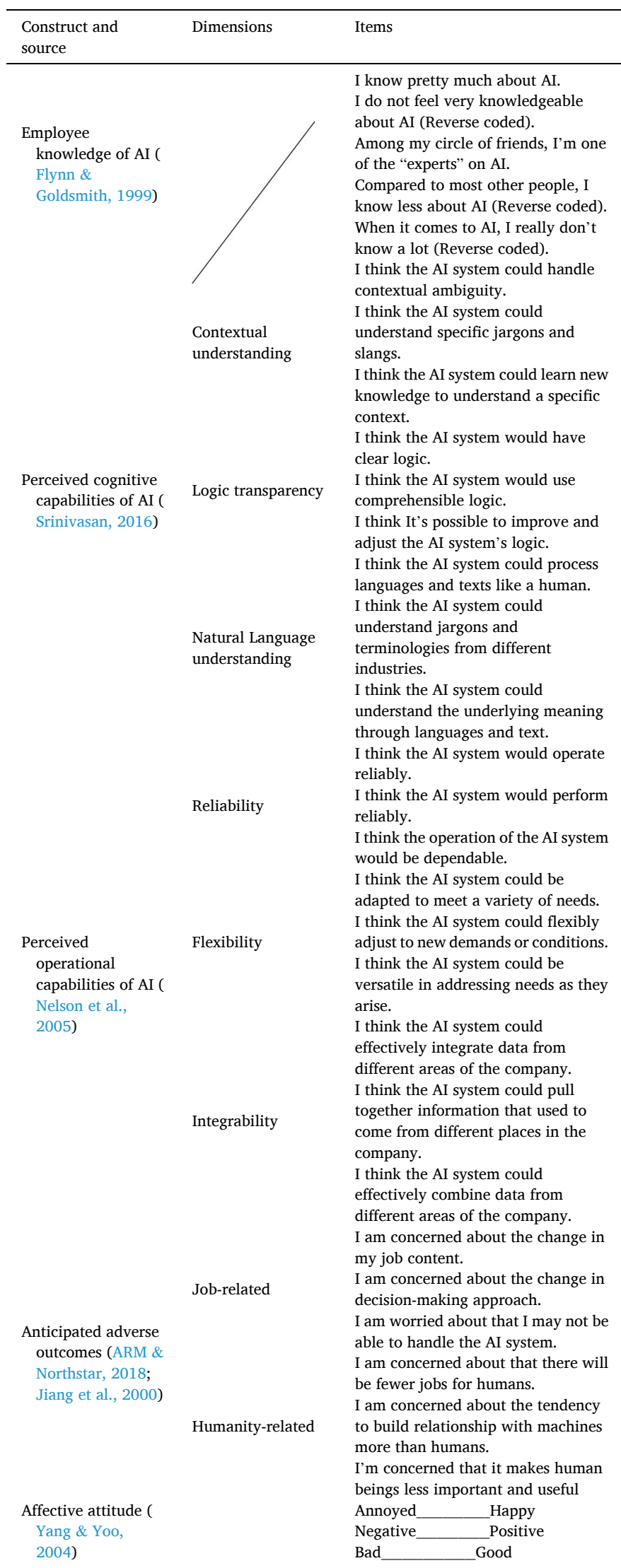

Table 4 (continued)

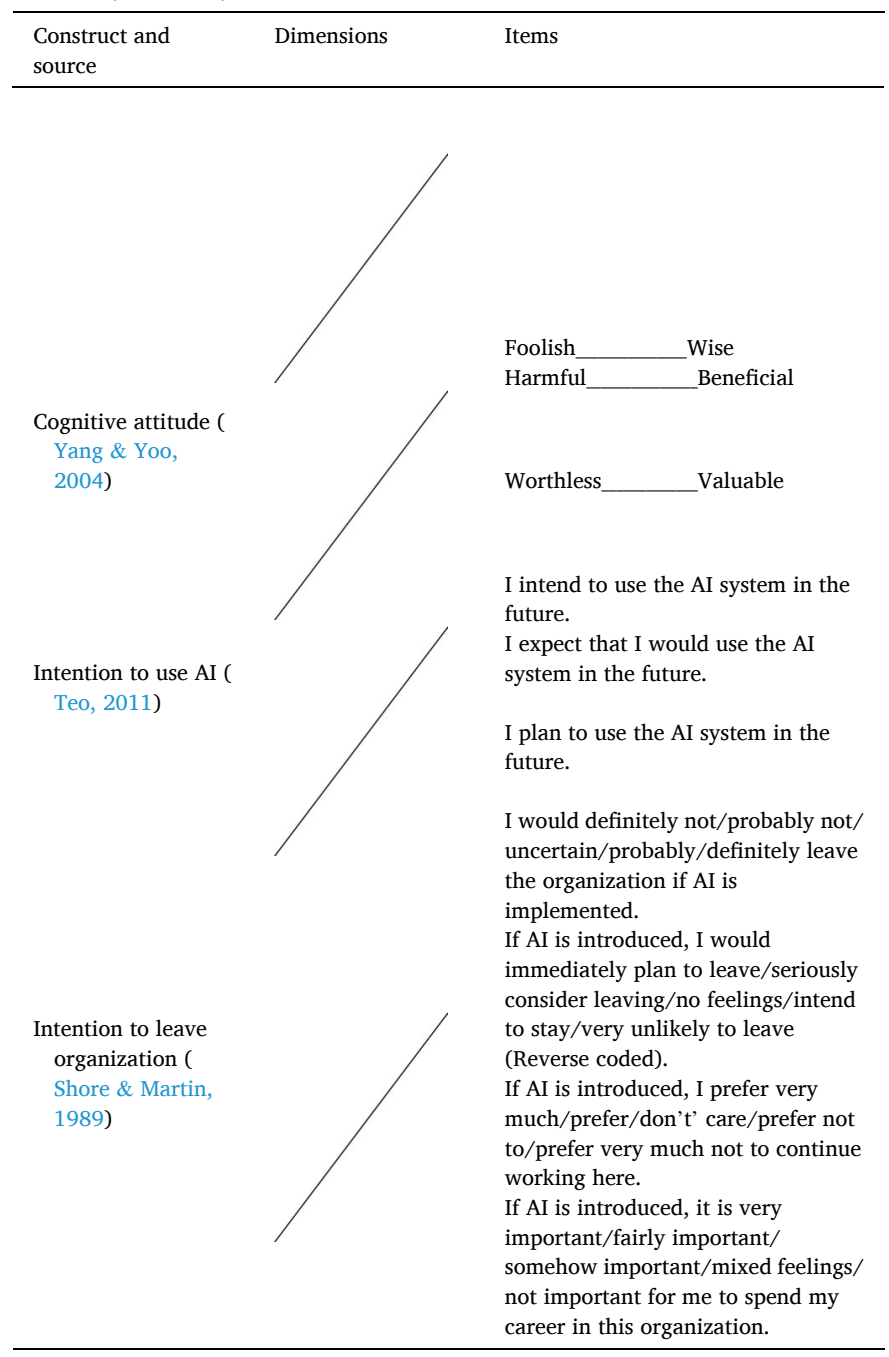

The three second-order constructs (perceived cognitive capability of AI, perceived operational capability of AI, and anticipated adverse outcomes) were modelled following the approaches of prior research (Pavlou \& Gefen, 2005; Salehan, Kim, \& Kim, 2017), with the first-order factor being reflective and second-order factor being formative. The results showed all first-order factors significantly loaded to their corresponding second-order factor $(\mathrm{p}<0.01$ ), supporting the use of second-order formative constructs in this study. We controlled for the age and gender of the respondents, as well as the respondents' position (management, non-management) and the knowledge intensity of the work.

Fig. 2 and Table 8 present the results of the structural model testing. The model explained a moderate amount of the variance in employees' intention to use $\mathrm{AI}$ in an enterprise context $\left(\mathrm{R}^{2}=0.39\right)$, but only a low proportion of employees' intention to leave $\left(\mathrm{R}^{2}=0.13\right)$.

With respect to employee knowledge, H1a and H1b were not supported at $\mathrm{p}<0.05$. Perceived operational capabilities and perceived cognitive capabilities of AI are significant predictors of both the affective and cognitive attitudes, supporting $\mathrm{H} 2$ to $\mathrm{H} 3$. Anticipated adverse outcomes of AI is negatively related to affective, but not cognitive attitudes. Thus, H4a received support, while H4b did not. Finally, affective attitude predicts both intentions to use AI and intention to leave the organization, while cognitive attitudes only relate to intentions to use AI. Therefore, H5a, H5b and H6a are supported.

Most of the control variables were not significant. However, the nature of an employee's work in terms of knowledge intensity was 
Table 5

Construct reliability and validity.

\begin{tabular}{|c|c|c|c|c|c|c|}
\hline Construct & Dimensions & Items & Loading & Cronbach's $\alpha$ & Composite Reliability & AVE \\
\hline \multirow{5}{*}{ Employee knowledge of AI } & & KN_1 & 0.88 & \multirow{5}{*}{0.92} & \multirow{5}{*}{0.94} & \multirow{5}{*}{0.77} \\
\hline & & KN_2 & 0.90 & & & \\
\hline & & KN_3 & 0.84 & & & \\
\hline & & KN_4 & 0.86 & & & \\
\hline & & KN_5 & 0.88 & & & \\
\hline \multirow{10}{*}{ Perceived cognitive capabilities of AI } & \multirow{4}{*}{ Contextual understanding } & CON_1 & 0.82 & \multirow{4}{*}{0.77} & \multirow{4}{*}{0.87} & \multirow{4}{*}{0.69} \\
\hline & & CON_2 & 0.85 & & & \\
\hline & & CON_3 & 0.82 & & & \\
\hline & & LOG_1 & 0.91 & & & \\
\hline & \multirow[t]{3}{*}{ Logic transparency } & LOG_2 & 0.91 & \multirow[t]{3}{*}{0.87} & \multirow[t]{3}{*}{0.92} & \multirow[t]{3}{*}{0.80} \\
\hline & & LOG_3 & 0.86 & & & \\
\hline & & LAN_1 & 0.83 & & & \\
\hline & \multirow[t]{3}{*}{ Natural Language understanding } & LAN_2 & 0.87 & \multirow[t]{3}{*}{0.81} & \multirow[t]{3}{*}{0.89} & \multirow[t]{3}{*}{0.72} \\
\hline & & LAN_3 & 0.84 & & & \\
\hline & & REL_1 & 0.92 & & & \\
\hline \multirow{8}{*}{ Perceived operational capabilities of AI } & \multirow{3}{*}{ Reliability } & REL_2 & 0.94 & \multirow{3}{*}{0.93} & \multirow[t]{3}{*}{0.96} & \multirow[t]{3}{*}{0.88} \\
\hline & & REL_3 & 0.94 & & & \\
\hline & & FLE_1 & 0.88 & & & \\
\hline & Flexibility & FLE_2 & 0.90 & 0.87 & 0.92 & 0.79 \\
\hline & & FLE_3 & 0.89 & & & \\
\hline & & INT_1 & 0.92 & & & \\
\hline & Integrability & INT_2 & 0.93 & 0.91 & 0.95 & 0.85 \\
\hline & & INT_3 & 0.92 & & & \\
\hline & & WC_1 & 0.87 & & & \\
\hline & Job-related & WC_2 & 0.84 & 0.78 & 0.87 & 0.69 \\
\hline & & WC_3 & 0.68 & & & \\
\hline Anticipated adverse outcomes & & RC_1 & 0.79 & & & \\
\hline & Humanitv-related & $\mathrm{RC}_{-} 2$ & 0.88 & 080 & 0.88 & 0.71 \\
\hline & TItum & RC_3 & 0.87 & 0.00 & 0.00 & 0.11 \\
\hline & & ATTA_1 & 0.90 & & & \\
\hline & & ATTA_2 & 0.91 & & & \\
\hline Affective attitude & & & & 0.89 & 0.93 & 0.81 \\
\hline & & ATTA_3 & 0.91 & & & \\
\hline & & ATTC_1 & 0.88 & & & \\
\hline & & ATTC_2 & 0.91 & & & \\
\hline Cognitive attitude & & & & 0.88 & 0.93 & 0.81 \\
\hline & & ATTC_3 & 0.92 & & & \\
\hline & & ITU_1 & 0.92 & & & \\
\hline & & ITU_2 & 0.95 & & & \\
\hline Intention to use enterprise AI & & & & 0.91 & 0.94 & 0.85 \\
\hline & & ITU_3 & 0.89 & & & \\
\hline & & TI_1 & 0.84 & & & \\
\hline & & TI_2 & 0.87 & & & \\
\hline & & TI_3 & 0.90 & & & \\
\hline Intention to leave organization & & & & 0.87 & 0.91 & 0.73 \\
\hline & & TI_4 & 0.79 & & & \\
\hline
\end{tabular}

significantly related to turnover intentions (at $\mathrm{p}<0.05$ ) with people who report themselves as in more knowledge-intensive jobs have lower intentions to leave $(b=-0.11, p<0.05)$.

\subsection{Post-hoc analyses}

As several hypotheses (H1a, H1b, H4a, H6b) were not supported, we conducted moderation tests to examine the possible interactions that could have rendered these insignificant results. For the relationship 
Table 6

Correlations.

\begin{tabular}{|c|c|c|c|c|c|c|c|c|c|c|c|c|c|}
\hline & $\mathrm{KN}$ & REL & FLE & INT & $\mathrm{CON}$ & LAN & LOG & JC & $\mathrm{HC}$ & ATTA & ATTC & ITU & TI \\
\hline $\mathrm{KN}$ & 0.88 & & & & & & & & & & & & \\
\hline REL & 0.14 & 0.94 & & & & & & & & & & & \\
\hline FLE & 0.08 & 0.65 & 0.89 & & & & & & & & & & \\
\hline INT & 0.07 & 0.58 & 0.60 & 0.92 & & & & & & & & & \\
\hline $\mathrm{CON}$ & 0.05 & 0.52 & 0.57 & 0.48 & 0.83 & & & & & & & & \\
\hline LAN & 0.05 & 0.51 & 0.58 & 0.57 & 0.74 & 0.85 & & & & & & & \\
\hline LOG & 0.08 & 0.51 & 0.52 & 0.62 & 0.57 & 0.58 & 0.89 & & & & & & \\
\hline JC & -0.19 & 0.17 & 0.17 & 0.16 & 0.05 & 0.14 & 0.15 & 0.83 & & & & & \\
\hline $\mathrm{HC}$ & -0.16 & 0.12 & 0.11 & 0.15 & -0.01 & 0.09 & 0.12 & 0.62 & 0.84 & & & & \\
\hline ATTA & 0.21 & 0.37 & 0.39 & 0.41 & 0.36 & 0.35 & 0.39 & -0.15 & -0.25 & 0.90 & & & \\
\hline ATTC & 0.16 & 0.47 & 0.44 & 0.60 & 0.39 & 0.42 & 0.46 & 0.01 & -0.02 & 0.77 & 0.90 & & \\
\hline ITU & 0.13 & 0.44 & 0.38 & 0.51 & 0.33 & 0.38 & 0.50 & -0.02 & -0.02 & 0.55 & 0.60 & 0.92 & \\
\hline TI & 0.04 & -0.08 & -0.14 & -0.21 & -0.04 & -0.06 & -0.23 & -0.01 & 0.00 & -0.30 & -0.26 & -0.26 & 0.85 \\
\hline
\end{tabular}

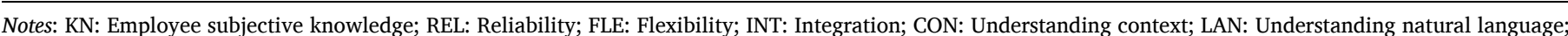

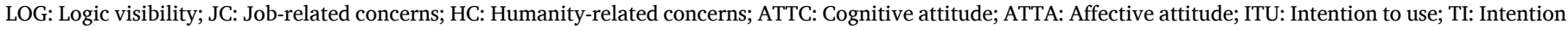
to leave organization.

The bold numbers on the diagonal are the square roots of the AVEs. The off-diagonals are correlations among constructs.

Table 7

Multicollinearity analysis.

\begin{tabular}{lll}
\hline Constructs & Tolerance & VIF \\
\hline Knowledge & 0.93 & 1.08 \\
Operational capabilities & 0.40 & 2.48 \\
Cognitive capabilities & 0.46 & 2.17 \\
Anticipated adverse outcomes & 0.79 & 1.27 \\
Cognitive attitude & 0.35 & 2.89 \\
Affective attitude & 0.35 & 2.89 \\
\hline
\end{tabular}

between anticipated adverse outcomes and cognitive attitude, we tested employee knowledge as a possible moderator. The results, illustrated in Fig. 3 and reported in Table 9, show that for employees with high subjective knowledge of AI, knowledge dampens the effects of anticipated adverse outcomes such that this anticipation does not lead to negative cognitive attitudes. Alternatively, for employees with low AI subjective knowledge of AI, anticipated adverse outcomes are likely to lower cognitive attitude toward AI.

For the relationship between cognitive attitude and intention to leave the organization, we tested affective attitude as a possible moderator. The results, illustrated in Fig. 4 and summarized in Table 8, show that for people with low affective attitude, high cognitive attitude does not seem to reduce turnover intentions, but for people with high affective attitude, high cognitive attitude reduces intentions of employees to leave their organization.

\section{Discussion}

This research investigates employees' pre-adoptive appraisals of AI. The hypothesized model received empirical support. We found that both the perceived operational and cognitive capabilities of AI are positively associated with affective and cognitive attitudes toward AI. This suggests the more employees believe AI will be able to deliver benefits such as reliability, flexibility, and integration with other systems, the more positive their attitudes are toward AI at both an emotional and a cognitive level. Similarly, perceptions regarding the ability of AI applications to understand human language and situational context and provide transparency into logical reasoning also enhance both dimensions of attitude. Perceived AI capabilities relevant for organizations because an understanding of how employees think and feel about AI

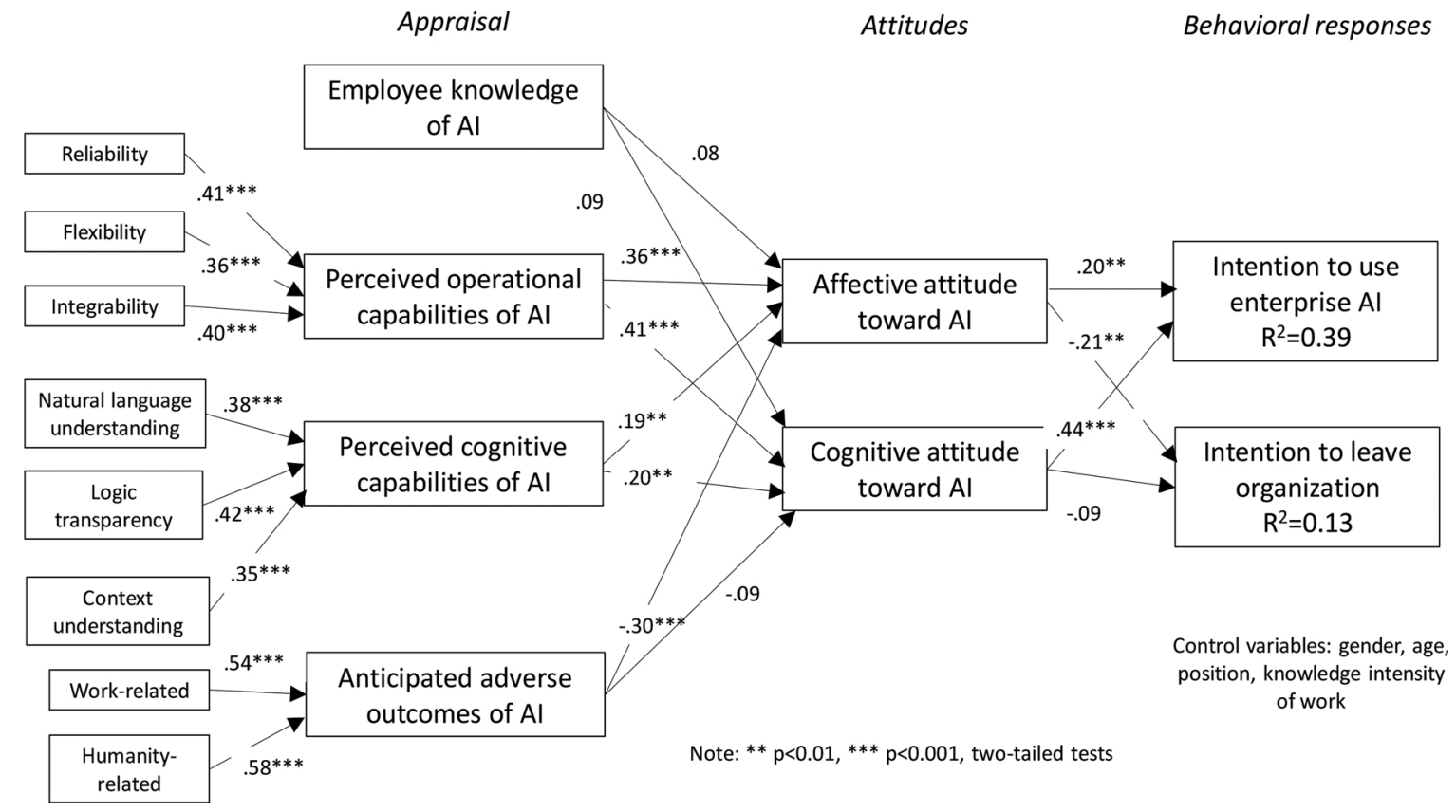

Fig. 2. Results. 
Table 8

Summary of hypothesis testing.

\begin{tabular}{|c|c|c|c|}
\hline Number & Hypothesis & Coefficient & Result \\
\hline $\mathrm{H} 1 \mathrm{a}$ & $\begin{array}{l}\text { Employee knowledge of } \mathrm{AI} \text { is positively } \\
\text { associated with affective attitude toward } \\
\text { AI. }\end{array}$ & 0.09 & $\begin{array}{l}\text { Not } \\
\text { supported }\end{array}$ \\
\hline $\mathrm{H} 1 \mathrm{~b}$ & $\begin{array}{l}\text { Employee knowledge of } \mathrm{AI} \text { is positively } \\
\text { associated with cognitive attitude toward } \\
\text { AI. }\end{array}$ & 0.08 & $\begin{array}{l}\text { Not } \\
\text { supported }\end{array}$ \\
\hline $\mathrm{H} 2 \mathrm{a}$ & $\begin{array}{l}\text { Perceived operational capabilities of AI } \\
\text { are positively associated with affective } \\
\text { attitude toward AI. }\end{array}$ & $0.36^{* * *}$ & Supported \\
\hline $\mathrm{H} 2 \mathrm{~b}$ & $\begin{array}{l}\text { Perceived operational capabilities of AI } \\
\text { are positively associated with cognitive } \\
\text { attitude toward AI. }\end{array}$ & $0.41^{* * *}$ & Supported \\
\hline H3a & $\begin{array}{l}\text { Perceived cognitive capabilities of AI are } \\
\text { positively associated with affective } \\
\text { attitude toward AI. }\end{array}$ & $0.19 * *$ & Supported \\
\hline H3b & $\begin{array}{l}\text { Perceived cognitive capabilities of AI are } \\
\text { positively associated with cognitive } \\
\text { attitude toward AI. }\end{array}$ & $0.20^{* *}$ & Supported \\
\hline $\mathrm{H} 4 \mathrm{a}$ & $\begin{array}{l}\text { Anticipated adverse outcomes of } \mathrm{AI} \text { are } \\
\text { negatively associated with affective } \\
\text { attitude toward AI. }\end{array}$ & $-0.30^{* * *}$ & Supported \\
\hline $\mathrm{H} 4 \mathrm{~b}$ & $\begin{array}{l}\text { Anticipated adverse outcomes of } \mathrm{AI} \text { are } \\
\text { negatively associated with cognitive } \\
\text { attitude toward AI. }\end{array}$ & -0.09 & $\begin{array}{l}\text { Not } \\
\text { supported }\end{array}$ \\
\hline $\mathrm{H} 5 \mathrm{a}$ & $\begin{array}{l}\text { Affective attitude toward } \mathrm{AI} \text { is positively } \\
\text { associated with intention to use enterprise } \\
\text { AI. }\end{array}$ & 0.20 ** & Supported \\
\hline $\mathrm{H} 5 \mathrm{~b}$ & $\begin{array}{l}\text { Cognitive attitude toward AI is positively } \\
\text { associated with intention to use enterprise } \\
\text { AI. }\end{array}$ & $0.44^{* * *}$ & Supported \\
\hline H6a & $\begin{array}{l}\text { Affective attitude toward AI is negatively } \\
\text { associated with intention to leave the } \\
\text { organization. }\end{array}$ & $-0.19 * *$ & Supported \\
\hline $\mathrm{H} 6 \mathrm{~b}$ & $\begin{array}{l}\text { Cognitive attitude toward } \mathrm{AI} \text { is negatively } \\
\text { associated with intention to leave the } \\
\text { organization. }\end{array}$ & -0.09 & $\begin{array}{l}\text { Not } \\
\text { supported }\end{array}$ \\
\hline
\end{tabular}

Note: $* *: \mathrm{p}<0.01 ; * * *: \mathrm{p}<0.001 ;$ two-tailed tests.

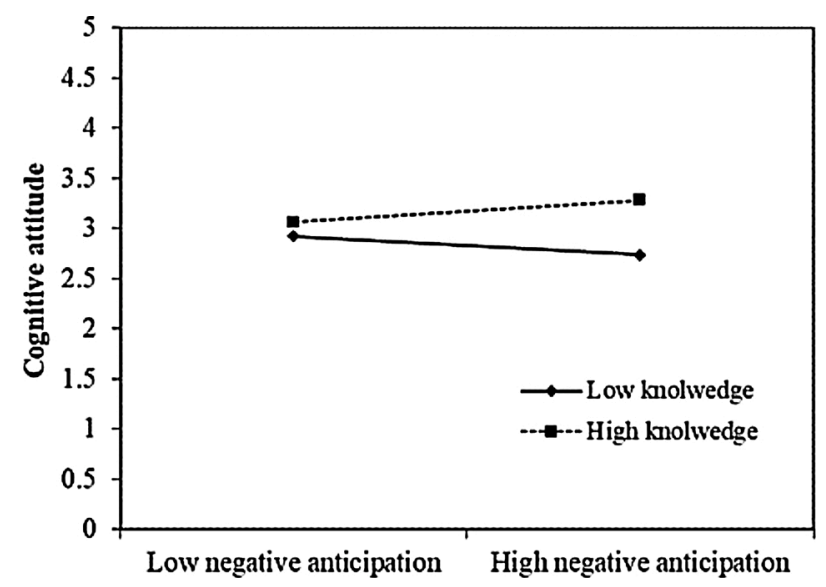

Fig. 3. Employee knowledge interaction with anticipated adverse outcomes.

capabilities can help to inform the design of AI. Although employees may not be equipped with sufficient knowledge to offer their insights into the design, their early attitudes indicate what they prefer. Specifically, our findings suggest that while both operational capabilities and cognitive capabilities shape positive attitudes, employees weigh operational capabilities more than cognitive capabilities of AI.

With respect to anticipated adverse outcomes, the results reveal that this concern influences affective attitude only. The finding is consistent with the cognitive appraisal theory where risk and threats can arouse emotions (Lazarus \& Folkman, 1984; Loewenstein et al., 2001). The lack of significant correlation with cognitive attitude, however, may be
Table 9

Interaction effects.

\begin{tabular}{lll}
\hline & Model 0 & Model 1 \\
\hline DV: Cognitive attitude & & \\
Knowledge & $.16^{* *}$ & $.17^{* *}$ \\
Anticipated adverse outcomes & .03 (n.s) & .01 (n.s) \\
Knowledge * Anticipated & & $.11^{* *}$ \\
$\mathrm{R}^{2}$ & .02 & .04 \\
$\mathrm{R}^{2}$ difference & & .01 \\
DV: Intention to leave & $-.24^{* *}$ & \\
Affective attitude & -.07 (n.s.) & $-.24^{* *}$ \\
Cognitive attitude & & $-.09(\mathrm{n} . \mathrm{s})$ \\
Affective*cognitive & .09 & $-.11^{*}$ \\
$\mathrm{R}^{2}$ & & .10 \\
$\mathrm{R}^{2}$ difference & & .01 \\
\hline
\end{tabular}

Note: $* \mathrm{p}<0.05 ;{ }^{* *}: \mathrm{p}<0.01 ;{ }^{* * *}: \mathrm{p}<0.001$

attributed to the complexity of human attitudes and individual differences. Some employees may hold ambivalent attitudes, that is, the existence of both positive and negative attitudes toward AI simultaneously (Conner \& Sparks, 2002). For instance, despite employees' concerns about AI's impacts on jobs and society, employees may appraise AI positively because they agree that AI will benefit the organization.

Consistent with expectations, the findings show both affective and cognitive attitudes relate to employees' behavioral responses to the technology (intention to use) and the organization (intention to leave). While intentions to use AI is driven by both affective and cognitive attitude, intention to leave an organization seems to be mostly emotionally charged, an extreme response to cope with a stressful situation (Armstrong-Stassen, 1994). When employees have a low affective attitude, their turnover intentions remain relatively stable regardless of their cognitive attitude. However, more positive feelings toward AI can amplify the effects of a positive cognitive attitude and reduce employees' intentions to leave the organization.

While many aspects of the model were confirmed, the expected relationship between employee knowledge and attitudes was not. This result is somewhat surprising because the extant research suggests people's attitudes are formed by what they know about an innovation (e. g., product, service, technology) (Aertsens et al., 2011; Ashari, Ngadiman, Zainudin, \& Jumaat, 2018). There may be a number of reasons for this finding. First, we chose to measure employees' subjective, rather than objective, knowledge. Although there is a moderate correlation between subjective and objective knowledge (Carlson et al., 2008), this relationship is weaker when the subject of knowledge is more complex and difficult to grasp clearly and concisely (Klerck \& Sweeney, 2007). AI fits within this category, as many employees may not be able to fully grasp the idea of how an algorithm can 'think' as we understand it in a human sense. There could be distortions and instability in employees' subjective knowledge, such that it has less impact on their cognitive and affective attitudes. Although objective knowledge is more difficult to measure within a research setting (Carlson et al., 2008), this may be a fruitful avenue to pursue both for researchers - to see if there is an impact - and managers - to determine employees' actual level of understanding of AI applications and capabilities.

Second, our post-hoc analysis reveals knowledge has an indirect impact on cognitive and affective attitudes and behaviors responses, rather than a direct effect. An employee having a high expectation of adverse outcomes combined with a high level of knowledge of AI is less likely to have low (negative) cognitive attitudes. This may occur because knowledge allows the employee to understand the continuing advances of AI technology and emerging techniques for mitigating unintended adverse consequences. On the other hand, when employees have low knowledge of AI, their cognitive attitude will be lower because they do not understand the potential and limits of the technology. In effect, knowledge seems to bolster cognitive appraisals and the lack of knowledge allows affective appraisals to gain amplitude. 


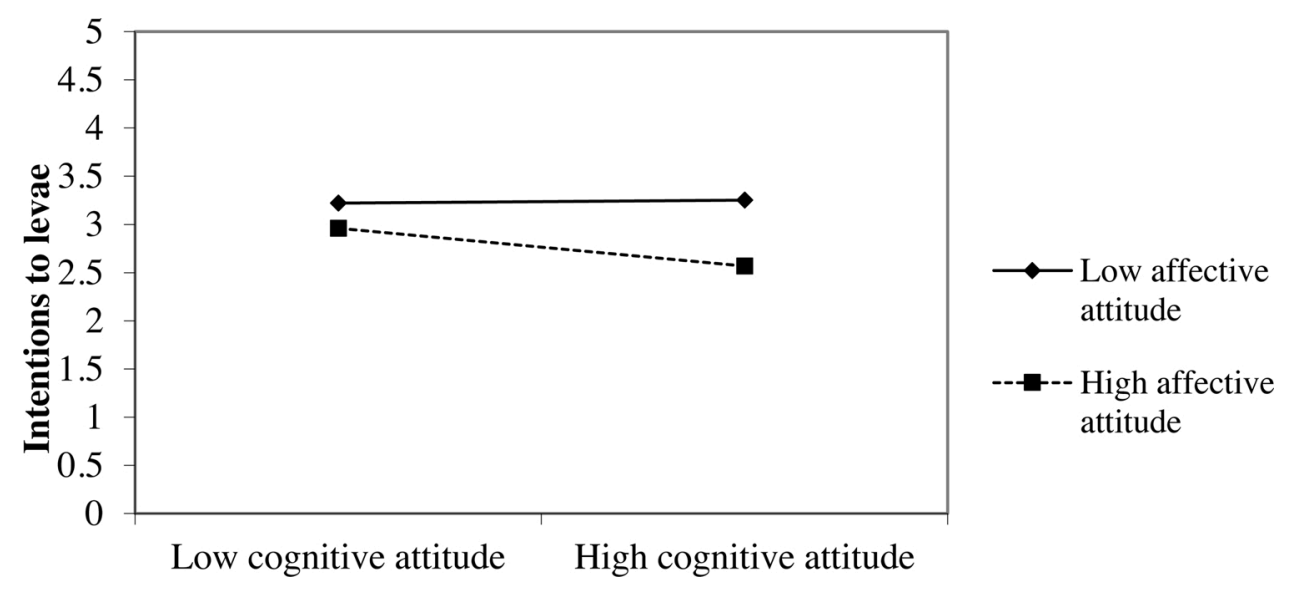

Fig. 4. Affective attitude interacts with cognitive attitude.

\subsection{Contributions to research}

The age of AI is upon us, however, there has been limited research conducted on how employees view their jobs in light of the rapid advancement of technologies including smart systems, AI, automation, robotics, and algorithms (Brougham \& Haar, 2017; Duan et al., 2019; Dwivedi et al., 2021). We extend scholarship by offering a theoretical framework and an empirically tested model of employees' pre-adoptive appraisals of AI, considering the operational and cognitive capabilities of AI, as well as the anticipated adverse effects on work and society that AI may have. This model can serve as a foundation for others seeking to understand the mixed attitudes and reactions of employees in the face of new technologies. In so doing, we set up micro-foundations for both organizational and design science researchers to understand how and why employees respond differently to $\mathrm{AI}$, including its design and impacts.

We also contribute to the literature by unpacking the complex relationships of cognitive evaluation of AI and explaining how and why users respond to ill-defined technologies like AI so differently. AI, imbued with human qualities concomitant with its versatility, evokes both positive and negative attitudes and behavioral responses. Enriching previous research on the impact of anticipated outcomes of general AI, this study conceptualizes the nature of AI into cognitive and operational capabilities. We reveal that during pre-adoptive appraisal, operational capability is a stronger predictor of users' attitudes, while cognitive capability, possibly due to technological limitations, appears to be less influencing in shaping users' attitudes.

Another contribution of this research is that it enriches an appraisalbased theory of IT by assessing both affective and cognitive attitudes. Previous research in enterprise technologies has tended to emphasize either cognitive or affective attitudes alone (Davis, Bagozzi, \& Warshaw, 1989; Zhang, 2013), while IS research using the cognitive appraisal theory is mainly interested in affective attitudes (Bhattacherjee et al., 2018; Osatuyi \& Qin, 2018). We contend the equivocal findings with respect to the influence of attitudes toward IS can be attributed to the lack of differentiation between thinking and feeling (Kroenung \& Eckhardt, 2017; Yang \& Yoo, 2004). In contrast, our findings show the important mediating role of both types of attitudes between appraisals and responses. Distinguishing affective from cognitive attitudes helps to shed new light on the study of attitudes toward transformative technologies. It illuminates the interplay between thinking and feeling responses when people encounter disruptive technologies and demonstrate conflicted attitudes. Notably, the research reveals the differential effects of cognitive and affective attitudes on behavioral responses, in particular, that the decision to leave an organization has more emotional drivers than does the decision to use enterprise AI. The research also reveals interesting interactions between cognitive and affective attitudes.

\subsection{Implications for practice}

This research also has important implications for managers. The preadoption phase sets the stage for the success or failure of future technology implementations (Herold et al., 1995; Veiga et al., 2014), like AI. An understanding of pre-adoption employee attitudes is crucial to managing the AI deployment process. Our research shows a mix of positive and negative evaluations by employees. Positive attitudes can be leveraged to build productive partnerships between AI and employees whereas negative attitudes, once developed, can be challenging to rectify (Chan, Jones, Hall Jamieson, \& Albarracín, 2017). We suggest that managers invest time in getting to know employees' existing cognitive and affective attitudes first because different types of attitudes demand different strategies (see Albarracin \& Shavitt, 2018 for more discussion).

A second implication concerns how $\mathrm{AI}$ is communicated throughout the organization. While this research did not investigate how employees' perceptions regarding the capabilities of AI are formed, information published in the public media and social networks, as well as personal experience with AI applications, such as social robots (De Graaf \& Allouch, 2013), AI-enabled call centers (Noonan \& Jenkins, 2019) or other AI applications, likely play an essential role. Organizations, therefore, must be aware of the discourse surrounding AI within their employees' relevant communities to understand the nature of employees' perceptions. We observe that operational capabilities have higher correlations with both dimensions of attitudes than cognitive capabilities and AI concerns. Thus, for most employees, operational functions are still the key for attitude development, highlighting the pragmatic side of employees in organizations. Accordingly, communications regarding enterprise AI applications should emphasize more traditional capabilities to generate more favorable attitudes.

Lastly, the results provide actionable insights regarding structural supports for employees prior to the adoption of AI. Managers need to understand what potential concerns could arise and plan accordingly to handle issues and avoid user resistance that could lead to project failure (Meissonier \& Houzé, 2010). During pre-adoption, organizations may start to experience skill shortages as employees leave the most vulnerable positions before the technology is implemented and fully matured. Therefore, employers need to offer appropriate training and resources, including proactive career planning (Brougham \& Haar, 2017), to help them cope with stressful situation. These communications and interventions need to be tailored to different types of positions within the organization. With proactive and personalized interventions, organizations are more likely to retain key employees. 


\subsection{Limitations and future research}

A first limitation is that the sample used for testing the conceptual model was limited to Taiwan. Nevertheless, similar to other developed economies, Taiwan is highly industrialized, and the data cover a wide range of industries. Thus, we contend that the results should be generalizable to other countries as employees experience similar pre-adoptive appraisal processes of AI. Future research can replicate this study and testing the model in different countries would enhance the theory and provide new insights into potential boundary conditions. For instance, organizations in Taiwan, like other countries with collectivist culture (Hofstede, 2020), have higher job security. In other countries, the model may show stronger explanatory power, particularly with respect to intention to leave, because employees in the lower job security context may experience stronger negative cognitive appraisals.

A second limitation is that this research adopts a cross-sectional research design. Although the literature suggest pre-adoptive appraisal have lasting effects (Chan et al., 2017), the research does not answer the question as to whether the observed effects remain constant over the different adoption phases. We suggest that future research should conduct a longitudinal study investigating how employees' appraisal of AI changes along the implementation process.

Third, this study investigates behavioral responses at two ends of the spectrum while fully acknowledging the many potential responses that exist in between. Employees may vary their degree of involvement in the technology implementation or use, or use other workarounds to deal with their concerns regarding AI (Bhattacherjee et al., 2018). Undoubtedly, there are nuanced responses that employees may take based on their attitude toward AI. Our theoretical understanding of AI, as well as the interventions implemented by organizations, will be improved if further options are investigated. We also acknowledge that human attitudes are intricate, especially facing a complex object like AI (Dang \& Liu, 2021). Future research can investigate the impact of ambivalent attitudes vis-à-vis non-ambivalent attitudes toward AI on behavioral response.

Finally, our study shows the emotional dimensions of AI cannot, and should not, be overlooked. The changing nature of work in the era of AI is not simply a cognitive, economic undertaking, but also an emotionally charged one. This affective dimension goes beyond the impacts on an affected individual to humanity as a whole. The ethical dimensions of AI implementation in business demand further investigation to ensure the responsible and sustainable design, development, implementation, and use of AI.

\section{Conclusion}

Over the coming years, organizations across all industries will face increasing pressure to implement AI to improve their performance and competitiveness. Employees' pre-adoptive attitudes toward this disruptive technology will influence the success of these implementation projects because they influence the extent to which employees' engagement in or resistance to AI implementation. Moreover, in certain cases, negative emotional attitudes can also lead employees to consider leaving their organization. This research has revealed how employees' knowledge of AI, their perceptions of AI capabilities and concerns regarding the negative impacts of $\mathrm{AI}$ influence cognitive and affective attitudes. We then show how these attitudes influence behavioral attentions. In addition to enriching theory, this research provides actionable guidance to managers as they prepare for the arrival of AI in their organizations.

Author's statement

Yi-Te Chiu: Conceptualization; Writing - original draft; Writing review \& editing; Project administration;

Yu-Qian Zhu: Conceptualization; Data curation; Formal analysis; Funding acquisition; Investigation; Methodology; Software; Validation; Visualization

Jacqueline Corbett: Conceptualization, Writing - original draft; Writing - review \& editing.

\section{Acknowledgement}

This work was supported by the Ministry of Science and Technology of Taiwan (Grant number: MOST-109-2410-H-011-011-MY3).

Appendix Loading and cross loading of items

\begin{tabular}{|c|c|c|c|c|c|c|c|c|c|c|c|c|c|}
\hline & ATTC & ATTA & JC & $\mathrm{HC}$ & ITU & $\mathrm{KN}$ & CON & FLE & INT & LAN & LOG & REL & TI \\
\hline ATTC_1 & 0.87 & 0.66 & 0.05 & -0.02 & 0.48 & 0.11 & 0.37 & 0.42 & 0.42 & 0.40 & 0.40 & 0.46 & -0.19 \\
\hline ATTC_2 & 0.92 & 0.70 & -0.02 & -0.01 & 0.58 & 0.15 & 0.31 & 0.40 & 0.47 & 0.38 & 0.41 & 0.40 & -0.28 \\
\hline ATTC_3 & 0.91 & 0.71 & 0.01 & -0.02 & 0.57 & 0.17 & 0.37 & 0.37 & 0.42 & 0.36 & 0.42 & 0.43 & -0.23 \\
\hline ATTA_1 & 0.67 & 0.90 & -0.15 & -0.27 & 0.48 & 0.15 & 0.36 & 0.35 & 0.36 & 0.33 & 0.31 & 0.35 & -0.25 \\
\hline ATTA_2 & 0.69 & 0.91 & -0.13 & -0.20 & 0.50 & 0.19 & 0.33 & 0.35 & 0.39 & 0.29 & 0.36 & 0.31 & -0.27 \\
\hline ATTA_3 & 0.72 & 0.91 & -0.14 & -0.21 & 0.51 & 0.21 & 0.30 & 0.34 & 0.37 & 0.31 & 0.37 & 0.35 & -0.29 \\
\hline JC_1 & 0.00 & -0.14 & 0.89 & 0.55 & -0.02 & -0.18 & 0.05 & 0.17 & 0.17 & 0.13 & 0.14 & 0.18 & -0.05 \\
\hline JC_2 & 0.05 & -0.10 & 0.88 & 0.50 & 0.03 & -0.11 & 0.06 & 0.17 & 0.21 & 0.14 & 0.19 & 0.15 & -0.08 \\
\hline JC_3 & -0.03 & -0.15 & 0.73 & 0.41 & -0.02 & -0.17 & -0.01 & 0.02 & 0.04 & -0.01 & -0.01 & 0.03 & 0.07 \\
\hline HC_1 & -0.01 & -0.24 & 0.58 & 0.87 & -0.06 & -0.16 & 0.06 & 0.15 & 0.09 & 0.16 & 0.12 & 0.15 & 0.06 \\
\hline HC_2 & -0.03 & -0.19 & 0.45 & 0.84 & -0.03 & -0.13 & 0.00 & 0.11 & 0.15 & 0.05 & 0.09 & 0.08 & -0.05 \\
\hline $\mathrm{HC}_{-} 3$ & -0.01 & -0.20 & 0.45 & 0.82 & 0.00 & -0.15 & -0.01 & 0.07 & 0.12 & 0.11 & 0.12 & 0.13 & 0.05 \\
\hline ITU_1 & 0.59 & 0.52 & 0.00 & -0.04 & 0.92 & 0.14 & 0.32 & 0.39 & 0.47 & 0.35 & 0.45 & 0.46 & -0.24 \\
\hline ITU_2 & 0.57 & 0.54 & 0.00 & -0.03 & 0.95 & 0.12 & 0.32 & 0.39 & 0.50 & 0.38 & 0.48 & 0.42 & -0.29 \\
\hline ITU_3 & 0.49 & 0.46 & 0.00 & -0.03 & 0.89 & 0.09 & 0.26 & 0.28 & 0.43 & 0.32 & 0.43 & 0.33 & -0.18 \\
\hline KN_1 & 0.21 & 0.22 & -0.14 & -0.15 & 0.18 & 0.88 & 0.09 & 0.12 & 0.11 & 0.11 & 0.16 & 0.19 & -0.04 \\
\hline KN_2 & 0.12 & 0.17 & -0.19 & -0.15 & 0.07 & 0.90 & -0.01 & 0.01 & 0.04 & -0.01 & 0.04 & 0.11 & 0.05 \\
\hline KN_3 & 0.11 & 0.17 & -0.12 & -0.16 & 0.11 & 0.84 & 0.11 & 0.14 & 0.04 & 0.06 & 0.02 & 0.13 & 0.07 \\
\hline KN_4 & 0.14 & 0.18 & -0.18 & -0.16 & 0.12 & 0.86 & -0.01 & 0.02 & 0.05 & 0.02 & 0.04 & 0.09 & 0.05 \\
\hline KN_5 & 0.10 & 0.14 & -0.18 & -0.16 & 0.03 & 0.88 & 0.02 & 0.02 & 0.01 & 0.01 & 0.03 & 0.06 & 0.08 \\
\hline CON_1 & 0.23 & 0.24 & 0.01 & 0.03 & 0.17 & 0.04 & 0.82 & 0.51 & 0.30 & 0.60 & 0.35 & 0.39 & 0.02 \\
\hline CON_2 & 0.33 & 0.29 & 0.02 & 0.02 & 0.30 & 0.01 & 0.85 & 0.43 & 0.44 & 0.65 & 0.50 & 0.46 & -0.03 \\
\hline CON_3 & 0.40 & 0.37 & 0.08 & 0.00 & 0.33 & 0.07 & 0.82 & 0.49 & 0.43 & 0.59 & 0.56 & 0.45 & -0.09 \\
\hline FLE_1 & 0.40 & 0.32 & 0.18 & 0.13 & 0.33 & 0.04 & 0.49 & 0.88 & 0.55 & 0.51 & 0.49 & 0.57 & -0.12 \\
\hline FLE_2 & 0.36 & 0.33 & 0.11 & 0.12 & 0.36 & 0.07 & 0.54 & 0.90 & 0.48 & 0.51 & 0.42 & 0.56 & -0.07 \\
\hline FLE_3 & 0.41 & 0.37 & 0.11 & 0.09 & 0.33 & 0.10 & 0.50 & 0.89 & 0.55 & 0.51 & 0.48 & 0.60 & -0.18 \\
\hline
\end{tabular}




\begin{tabular}{|c|c|c|c|c|c|c|c|c|c|c|c|c|c|}
\hline & ATTC & ATTA & JC & $\mathrm{HC}$ & ITU & $\mathrm{KN}$ & CON & FLE & INT & LAN & LOG & REL & TI \\
\hline INT_1 & 0.45 & 0.39 & 0.18 & 0.14 & 0.47 & 0.08 & 0.45 & 0.58 & 0.92 & 0.52 & 0.58 & 0.53 & -0.20 \\
\hline INT_2 & 0.46 & 0.38 & 0.15 & 0.09 & 0.49 & 0.05 & 0.42 & 0.53 & 0.93 & 0.52 & 0.56 & 0.55 & -0.21 \\
\hline INT_3 & 0.44 & 0.37 & 0.15 & 0.16 & 0.45 & 0.06 & 0.45 & 0.54 & 0.92 & 0.53 & 0.56 & 0.52 & -0.18 \\
\hline LAN_1 & 0.41 & 0.33 & 0.04 & 0.09 & 0.33 & 0.05 & 0.54 & 0.53 & 0.51 & 0.82 & 0.50 & 0.48 & -0.13 \\
\hline LAN_2 & 0.30 & 0.25 & 0.09 & 0.13 & 0.28 & 0.07 & 0.65 & 0.46 & 0.49 & 0.88 & 0.52 & 0.42 & 0.00 \\
\hline LAN_3 & 0.36 & 0.30 & 0.14 & 0.10 & 0.35 & 0.01 & 0.70 & 0.49 & 0.46 & 0.85 & 0.46 & 0.41 & -0.01 \\
\hline LOG_1 & 0.45 & 0.41 & 0.07 & 0.05 & 0.46 & 0.13 & 0.53 & 0.45 & 0.55 & 0.53 & 0.91 & 0.47 & -0.19 \\
\hline LOG_2 & 0.38 & 0.32 & 0.10 & 0.13 & 0.41 & 0.04 & 0.53 & 0.46 & 0.55 & 0.54 & 0.92 & 0.45 & -0.18 \\
\hline LOG_3 & 0.40 & 0.30 & 0.21 & 0.17 & 0.47 & 0.04 & 0.47 & 0.49 & 0.54 & 0.48 & 0.85 & 0.46 & -0.24 \\
\hline REL_1 1 & 0.45 & 0.35 & 0.15 & 0.14 & 0.42 & 0.16 & 0.46 & 0.59 & 0.52 & 0.45 & 0.46 & 0.92 & -0.08 \\
\hline REL_2 & 0.46 & 0.35 & 0.13 & 0.13 & 0.41 & 0.11 & 0.51 & 0.61 & 0.54 & 0.48 & 0.49 & 0.94 & -0.08 \\
\hline REL_3 & 0.43 & 0.35 & 0.15 & 0.14 & 0.42 & 0.13 & 0.49 & 0.63 & 0.55 & 0.51 & 0.49 & 0.94 & -0.06 \\
\hline TI_1 & -0.21 & -0.28 & 0.13 & 0.19 & -0.21 & -0.01 & 0.00 & -0.09 & -0.14 & -0.01 & -0.13 & -0.01 & 0.85 \\
\hline TI_2 & -0.20 & -0.23 & -0.05 & -0.03 & -0.24 & 0.09 & -0.04 & -0.10 & -0.20 & -0.06 & -0.23 & -0.06 & 0.88 \\
\hline TI_3 & -0.25 & -0.27 & -0.07 & -0.04 & -0.25 & 0.07 & -0.03 & -0.11 & -0.21 & -0.08 & -0.25 & -0.10 & 0.91 \\
\hline TI_4 & -0.22 & -0.24 & -0.13 & -0.05 & -0.19 & -0.02 & -0.08 & -0.19 & -0.16 & -0.04 & -0.16 & -0.10 & 0.77 \\
\hline
\end{tabular}

Notes: KN: Employee subjective knowledge; REL: Reliability; FLE: Flexibility; INT: Integration; CON: Understanding context; LAN: Understanding natural language; LOG: Logic visibility; JC: Job-related concerns; HC: Humanity-related concerns; ATTC: Cognitive attitude; ATTA: Affective attitude; ITU: Intention to use; TI: Intention to leave organization.

\section{References}

Abdullah, R., \& Fakieh, B. (2020). Health care employees' perceptions of the use of artificial intelligence applications: Survey study. Journal of Medical Internet Research, 22, Article e17620.

Acemoglu, D., \& Restrepo, P. (2018). Artificial intelligence, automation and work, 2020. Cambridge, MA: National Bureau of Economic Research.

Aertsens, J., Mondelaers, K., Verbeke, W., Buysse, J., \& Van Huylenbroeck, G. (2011). The influence of subjective and objective knowledge on attitude, motivations and consumption of organic food. British Food Journal, 113, 1353-1378.

Albarracin, D., \& Shavitt, S. (2018). Attitudes and attitude change. Annual Review of Psychology, 69, 299-327.

Angst, C. M., \& Agarwal, R. (2009). Adoption of electronic health records in the presence of privacy concerns: The elaboration likelihood model and individual persuasion. MIS Quarterly, 33, 339-370.

Ardon, O., \& Schmidt, R. L. (2020). Clinical laboratory employees' attitudes toward artificial intelligence. Laboratory Medicine.

ARM, \& Northstar. (2018). Awareness, acceptance and anticipation of AI: A global consumer perspective. AI Today, AI Tomorrow.

Armstrong-Stassen, M. (1994). Coping with transition: A study of layoff survivors. Journal of Organizational Behavior, 15, 597-621.

Ashari, Z. M., Ngadiman, A. A., Zainudin, N. F., \& Jumaat, N. F. (2018). The relationship between knowledge and attitude towards technology gadget usage with students socio-emotions development. International Journal of Interactive Mobile Technologies, $12,152-163$.

Aspinwall, L. G. (2005). The psychology of future-oriented thinking: From achievement to proactive coping, adaptation, and aging. Motivation and Emotion, 29, 203-235.

Balakrishnan, J., \& Dwivedi, Y. K. (2021a). Role of cognitive absorption in building user trust and experience. Psychology \& Marketing, 38(4), 643-668.

Balakrishnan, J., \& Dwivedi, Y. K. (2021b). Conversational commerce: Entering the next stage of AI-powered digital assistants. Annals of Operations Research, 1-35. https:// doi.org/10.1007/s10479-021-04049-5.

Beaudry, A., \& Pinsonneault, A. (2005). Understanding user responses to information technology: A coping model of user adaptation. MIS Quarterly, 29, 493-524.

Beaudry, A., \& Pinsonneault, A. (2010). The other side of acceptance: Studying the direct and indirect effects of emotions on information technology use. MIS Quarterly, 34, 689-710.

Bhattacherjee, A., Davis, C. J., Connolly, A. J., \& Hikmet, N. (2018). User response to mandatory IT use: A coping theory perspective. European Journal of Information Systems, 27, 395-414.

Bohannon, J. (2015). Fears of an AI pioneer. Sciene, 349, 252.

Borges, A. F., Laurindo, F. J., Spínola, M. M., Gonçalves, R. F., \& Mattos, C. A. (2021). The strategic use of artificial intelligence in the digital era: Systematic literature review and future research directions. International Journal of Information Management, 1-16.

Brock, J. K.-U., \& von Wangenheim, F. (2019). Demystifying AI: What digital transformation leaders can teach you about realistic artificial intelligence. Californid Management Review, 61, 110-134.

Brougham, D., \& Haar, J. (2017). Employee assessment of their technological redundancy. Labour \& Industry A Journal of the Social and Economic Relations of Work 27, 213-231.

Brougham, D., \& Haar, J. (2018). Smart technology, artificial intelligence, robotics, and algorithms (STARA): Employees' perceptions of our future workplace. Journal of Management \& Organization, 24, 239-257.

Brucks, M. (1985). The effects of product class knowledge on information search behavior. The Journal of Consumer Research, 12, 1-16.
Brynjolfsson, E., \& McAfee, A. (2017). The business of artificial intelligence, 2020. Harvard business review.

Carlson, J. P., Vincent, L. H., Hardesty, D. M., \& Bearden, W. O. (2008), Objective and subjective knowledge relationships: A quantitative analysis of consumer research findings. The Journal of Consumer Research, 35, 864-876.

Chan, M.-p. S., Jones, C. R., Hall Jamieson, K., \& Albarracín, D. (2017). Debunking: A meta-analysis of the psychological efficacy of messages countering misinformation. Psychological Science, 28, 1531-1546.

Choi, J. N., Sung, S. Y., Lee, K., \& Cho, D. S. (2011). Balancing cognition and emotion: Innovation implementation as a function of cognitive appraisal and emotional reactions toward innovation. Journal of Organizational Behavior, 32, 107-124.

Chui, M., \& Malhotra, S. (2018). AI adoption advances, but foundational barriers remain, 2020. McKinsey \& Company.

Conner, M., \& Sparks, P. (2002). Ambivalence and attitudes. European Review of Social Psychology, 12, 37-70.

Craig, K., Thatcher, J. B., \& Grover, V. (2019). The IT identity threat: A conceptual definition and pperational measure. Journal of Management Information Systems, 36, 259-288.

D'Mello, S. K., Graesser, A., \& King, B. (2010). Toward spoken human-computer tutorial dialogues. Human-Computer Interaction, 25, 289-323.

Dang, J., \& Liu, L. (2021). Robots are friends as well as foes: Ambivalent attitudes toward mindful and mindless AI robots in the United States and China. Computers in Human Behavior, 115, Article 106612.

Davis, F. D., Bagozzi, R. P., \& Warshaw, P. R. (1989). User acceptance of computer technology: A comparison of two theoretical models. Management Science, 35, 982-1003.

De Graaf, M., \& Allouch, S. B. (2013). Exploring influencing variables for the acceptance of social robots. Robotics and Autonomous Systems, 61(12), 1476-1486.

Ding, Y. (2018). Modelling continued use of information systems from a forward-looking perspective: Antecedents and consequences of hope and anticipated regret. Information \& Management, 55, 461-471.

Duan, Y., Edwards, J. S., \& Dwivedi, Y. K. (2019). Artificial intelligence for decision making in the era of Big Data-evolution, challenges and research agenda. International Journal of Information Management, 48, 63-71.

Dwivedi, Y. K., Hughes, L., Ismagilova, E., Aarts, G., Coombs, C., Crick, T., Duan, Y., Dwivedi, R., Edwards, J., \& Eirug, A. (2021). Artificial Intelligence (AI): Multidisciplinary perspectives on emerging challenges, opportunities, and agenda for research, practice and policy. International Journal of Information Management, 57, Article 101994.

Dwivedi, Y. K., Rana, N. P., Jeyaraj, A., Clement, M., \& Williams, M. D. (2019). Reexamining the unified theory of acceptance and use of technology (UTAUT): Towards a revised theoretical model. Information Systems Frontiers, 21, 719-734.

Edwards, K. (1990). The interplay of affect and cognition in attitude formation and change. Journal of Personality and Social Psychology, 59, 202-216.

Ellway, B. P. (2016). What's wrong with IVR system service? A spatial theorisation of customer confusion and frustration. Journal of Service Theory and Practice.

Fadel, K. J., \& Brown, S. B. (2010). Information systems appraisal and coping: The role of user perceptions. Communications of the Association for Information Systems, 26, 1-22.

Fast, E., \& Horvitz, E. (2017). Long-term trends in the public perception of artificial intelligence. Thirty-First AAAI Conference on Artificial Intelligence, 963-969.

Flynn, L. R., \& Goldsmith, R. E. (1999). A short, reliable measure of subjective knowledge. Journal of Business Research, 46, 57-66.

Fornell, C., \& Larcker, D. F. (1981). Evaluating structural equation models with unobservable variables and measurement error. Journal of Marketing Research, 18, $39-50$.

Fuscaldo, D. (2019). AI's Promise: $\$ 140$ Billion in Productivity Gains for Financial Services Firms, 2021. 
Griol, D., Molina, J. M., \& Callejas, Z. (2014). Modeling the user state for context-aware spoken interaction in ambient assisted living. Applied Intelligence, 40, 749-771.

Gupta, N., Fischer, A. R., \& Frewer, L. J. (2012). Socio-psychological determinants of public acceptance of technologies: A review. Public Understanding of Science, 21, $782-795$.

Gursoy, D., Chi, O. H., Lu, L., \& Nunkoo, R. (2019). Consumers acceptance of artificially intelligent (AI) device use in service delivery. International Journal of Information Management, 49, 157-169.

Herold, D. M., Farmer, S. M., \& Mobley, M. I. (1995). Pre-implementation attitudes toward the introduction of robots in a unionized environment. Journal of Engineering and Technology Management, 12, 155-173.

Hirsch, P. B. (2019). Tinker, tailor, soldier, spy. The Journal of Business Strategy, 40, 53-56.

Hofstede, G. (2020). National Culture Comparison Tool. Retrieved 15 August from htt ps://www.hofstede-insights.com/product/compare-countries/.

Hong, W., Chan, F. K., Thong, J. Y., Chasalow, L. C., \& Dhillon, G. (2014). A framework and guidelines for context-specific theorizing in information systems research. Information Systems Research, 25(1), 111-136.

Hoon, J. (2019). A decision support framework for robust R\&D budget allocation using machine learning and optimization. Decision Support Systems, 121, 1-12.

Howe, L. C., \& Krosnick, J. A. (2017). Attitude strength. Annual Review of Psychology, 68, 327-351.

Huang, M.-H., \& Rust, R. T. (2021). A strategic framework for artificial intelligence in marketing. Journal of the Academy of Marketing Science, 49, 30-50.

Huang, M.-H., Rust, R., \& Maksimovic, V. (2019). The feeling economy: Managing in the next generation of artificial intelligence (AI). California Management Review, 61, 43-65.

Hulland, J., Ryan, M. J., \& Rayner, R. K. (2010). Modeling customer satisfaction: A comparative performance evaluation of covariance structure analysis versus partial least squares. In V. E. Vinzi, W. W. Chin, J. Henseler, \& H. Wang (Eds.), Handbook of partial least squares (pp. 307-325). Berlin, Germany: Springer.

Jiang, J. J., Muhanna, W. A., \& Klein, G. (2000). User resistance and strategies for promoting acceptance across system types. Information \& Management, 37, 25-36.

Jimenez, J. (2018). 5 ways artificial intelligence can boost productivity, 2021. Industry Week.

Johns, G. (2006). The essential impact of context on organizational behavior. Academy of Management Review, 31(2), 386-408.

Kim, J., \& Kang, P. (2016). Late payment prediction models for fair allocation of customer contact lists to call center agents. Decision Support Systems, 85, 84-101.

Kim, M.-S., Kim, J., \& Thapa, B. (2018). Influence of environmental knowledge on affect, nature affiliation and pro-environmental behaviors among tourists. Sustainability, 10 3109.

Klerck, D., \& Sweeney, J. C. (2007). The effect of knowledge types on consumerperceived risk and adoption of genetically modified foods. Psychology \& Marketing, 24, 171-193.

Knickrehm, M. (2018). How will AI change work? Here are 5 schools of thought. Harvard Business Review.

Kroenung, J., \& Bernius, S. (2012). Four types of attitudes in ICT acceptance and use? A critical assessment on the basis of empirical and scientometric data. In 2012 45th Hawaii International Conference on System Sciences (pp. 3139-3148).

Kroenung, J., \& Eckhardt, A. (2017). What determines user attitudes in IS research? A meta-analytic structural equation modeling approach. Journal of Information Technology Theory and Application (JTTA), 18, 34-65.

Lai, V. S., \& Mahapatra, R. K. (1997). Exploring the research in information technology implementation. Information \& Management, 32, 187-201.

Lapointe, L., \& Rivard, S. (2017). Research on user resistance to information technology. The Routledge companion to management information systems (pp. 183-201). London, UK: Routledge.

Lazarus, R. S., \& Folkman, S. (1984). Stress, appraisal and coping. New York: Springer.

Legris, P., Ingham, J., \& Collerette, P. (2003). Why do people use information technology? A critical review of the technology acceptance model. Information \& Management, 40, 191-204.

Levy, F. (2018). Computers and populism: Artificial intelligence, jobs, and politics in the near term. Oxford Review of Economic Policy, 34, 393-417.

Li, J. J., Bonn, M. A., \& Ye, B. H. (2019). Hotel employee's artificial intelligence and robotics awareness and its impact on turnover intention: The moderating roles of perceived organizational support and competitive psychological climate. Tourism Management, 73, 172-181.

Liang, P. (2016). Learning executable semantic parsers for natural language understanding. Communications of the ACM, 59, 68-76.

Loewenstein, G. F., Weber, E. U., Hsee, C. K., \& Welch, N. (2001). Risk as feelings. Psychological Bulletin, 127, 267-286.

Mahlasela, S., \& Chinyamurindi, W. T. (2020). Technology-related factors and their influence on turnover intentions: A case of government employees in South Africa. The Electronic Journal of Information Systems in Developing Countries, 86, Article e12126.

Mansfield, E. R., \& Helms, B. P. (1982). Detecting multicollinearity. The American Statistician, 36, 158-160.

Matthews, G., Lin, J., Panganiban, A. R., \& Long, M. D. (2019). Individual differences in trust in autonomous robots: Implications for transparency. IEEE Transactions on Human-machine Systems.

Meissonier, R., \& Houzé, E. (2010). Toward an 'IT conflict-resistance theory': Action research during IT pre-implementation. European Journal of Information Systems, 19 540-561.
Mikalef, P., Pappas, I. O., Krogstie, J., Jaccheri, L., \& Rana, N. (2021). Editors' reflections and introduction to the special section on 'Artificial Intelligence and Business Value'. International Journal of Information Management, 57, 1-3.

Mittelstadt, B., Russell, C., \& Wachter, S. (2019). Explaining explanations in AI Proceedings of the Conference on Fairness, Accountability, and Transparency, 279-288.

Müller, V. C., \& Bostrom, N. (2016). Future progress in artificial intelligence: A survey of expert opinion. Fundamental issues of artificial intelligence (pp. 555-572). New York City, NY: Springer.

Nach, H., \& Lejeune, A. (2010). Coping with information technology challenges to identity: A theoretical framework. Computers in Human Behavior, 26, 618-629.

Nelson, R. R., Todd, P. A., \& Wixom, B. H. (2005). Antecedents of information and system quality: An empirical examination within the context of data warehousing. Journal of Management Information Systems, 21, 199-235.

Noonan, L., \& Jenkins, P. (2019). Citigroup CEO says machines could cut thousands of call centre jobs. FT.com. Retrieved February 21 from https://www.ft.com/content b04d502a-329c-11e9-bb0c-42459962a812.

Nowak, A., Lukowicz, P., \& Horodecki, P. (2018). Assessing artificial intelligence for humanity: Will AI be the our biggest ever advance? Or the biggest threat [Opinion]. IEEE Technology and Society Magazine, 37, 26-34.

Osatuyi, B., \& Qin, H. (2018). How vital is the role of affect on post-adoption behaviors? An examination of social commerce users. International Journal of Information Management, 40, 175-185.

Pan, Y., Froese, F., Liu, N., Hu, Y., \& Ye, M. (2021). The adoption of artificial intelligence in employee recruitment: The influence of contextual factors. International Journal of Human Resource Management, 1-23.

Papadopoulos, T., Baltas, K. N., \& Balta, M. E. (2020). The use of digital technologies by small and medium enterprises during COVID-19: Implications for theory and practice. International Journal of Information Management, 55, Article 102192.

Pavlou, P. A., \& Gefen, D. (2005). Psychological contract violation in online marketplaces: Antecedents, consequences, and moderating role. Information Systems Research, 16, 372-399.

Pisal, H., Sutar, S., Sastry, J., Kapadia-Kundu, N., Joshi, A., Joshi, M., et al. (2007). Nurses' health education program in India increases HIV knowledge and reduces fear. Journal of the Association of Nurses in AIDS Care, 18, 32-43.

Podsakoff, P. M., MacKenzie, S. B., \& Podsakoff, N. P. (2012). Sources of method bias in social science research and recommendations on how to control it. Annual Review of Psychology, 63, 539-569.

Prentice, C., Dominique Lopes, S., \& Wang, X. (2020). Emotional intelligence or artificial intelligence-an employee perspective. Journal of Hospitality Marketing \& Management, 29, 377-403.

Rahman, M. S., Ko, M., Warren, J., \& Carpenter, D. (2016). Healthcare Technology SelfEfficacy (HTSE) and its influence on individual attitude: An empirical study. Computers in Human Behavior, 58, 12-24.

Ringle, C. M., Sarstedt, M., \& Straub, D. W. (2012). Editor's comments: A critical look at the use of PLS-SEM in MIS Quarterly. MIS Quarterly, iii-xiv.

Ritter, N. L. (2017). Technology acceptance model of online learning management systems in higher education: A meta-analytic structural equation model. International Journal of Learning Management Systems, 5, 1-15.

Rogers, E. M. (2003). Diffusion of innovations (5th ed.). New York: Free Press, A Division of Simon \& Schuster, Inc.

Sabah, G. (2010). Natural language understanding: Where are we going? Where could we go? The Computer Journal, 54, 1505-1513.

Salehan, M., Kim, D. J., \& Kim, C. (2017). Use of online social networking services from a theoretical perspective of the motivation-participation-performance framework. Journal of the Association for Information Systems, 18, 1.

Schepers, J., \& Wetzels, M. (2007). A meta-analysis of the technology acceptance model: Investigating subjective norm and moderation effects. Information \& Management, 44, 90-103.

Scherer, R., Siddiq, F., \& Tondeur, J. (2019). The technology acceptance model (TAM): A meta-analytic structural equation modeling approach to explaining teachers' adoption of digital technology in education. Computers \& Education, 128, 13-35.

Schwarzer, R., \& Knoll, N. (2003). Positive coping: Mastering demands and searching for meaning. Positive psychological assessment: A handbook of models and measures (pp. 393-409). Washington, DC, US: American Psychological Association.

Shore, L. M., \& Martin, H. J. (1989). Job satisfaction and organizational commitment in relation to work performance and turnover intentions. Human Relations, 42, 625-638.

Srinivasan, V. (2016). Context, language, and reasoning in AI: Three key challenges, 2020. MIT technology review.

ŠUmak, B., HeričKo, M., \& PušNik, M. (2011). A meta-analysis of e-learning technology acceptance: The role of user types and e-learning technology types. Computers in Human Behavior, 27, 2067-2077.

Sun, T. Q., \& Medaglia, R. (2019). Mapping the challenges of Artificial Intelligence in the public sector: Evidence from public healthcare. Government Information Quarterly, 36, 368-383.

Tarafdar, M., Beath, C. M., \& Ross, J. W. (2017). Enterprise cognitive computing applications: Opportunities and challenges. IT Professional Magazine, 19, 21-27.

Tarafdar, M., Beath, C. M., \& Ross, J. W. (2019). Using AI to enhance business operations. MIT Sloan Management Review, Summer 2019, 37-44.

Teo, T. (2011). Factors influencing teachers' intentions to use technology: Model development and test. Computers \& Education, 57, 2432-2440.

Teradata. (2017). State of artificial intelligence for enterprises. San Diego, CA: Teradata.

Thompson, M. (2012). People, practice, and technology: Restoring Giddens' broader philosophy to the study of information systems. Information and Organization, 22, 188-207. 
Van der Heijden, H. (2004). User acceptance of hedonic information systems. MIS Quarterly, 28, 695-704.

Veiga, J. F., Keupp, M. M., Floyd, S. W., \& Kellermanns, F. W. (2014). The longitudina impact of enterprise system users' pre-adoption expectations and organizational support on post-adoption proficient usage. European Journal of Information Systems, $23,691-707$.

Venkatesh, V. (2021). Adoption and use of AI tools: A research agenda grounded in UTAUT. Annals of Operations Research, 1-12.

Vimalkumar, M., Sharma, S. K., Singh, J. B., \& Dwivedi, Y. K. (2021). 'Okay google, what about my privacy?': User's privacy perceptions and acceptance of voice based digital assistants. Computers in Human Behavior, 120, Article 106763.

Walsham, G. (1998). IT and changing professional identity: Micro-studies and macrotheory. Journal of the American Society for Information Science, 49, 1081-1089.
Wang, X., Wang, L., Zhang, L., Xu, X., Zhang, W., \& Xu, Y. (2017). Developing an employee turnover risk evaluation model using case-based reasoning. Information Systems Frontiers, 19, 569-576.

Wu, J., \& Lu, X. (2013). Effects of extrinsic and intrinsic motivators on using utilitarian, hedonic, and dual-purposed information systems: A meta-analysis. Journal of the Association for Information Systems, 14, 153-191.

Yang, H.-d., \& Yoo, Y. (2004). It's all about attitude: Revisiting the technology acceptance model. Decision Support Systems, 38, 19-31.

Zhang, P. (2013). The affective response model: A theoretical framework of affective concepts and their relationships in the ICT context. MIS Quarterly, 247-274.

Zhang, L., Zhu, J., \& Liu, Q. (2012). A meta-analysis of mobile commerce adoption and the moderating effect of culture. Computers in Human Behavior, 28, 1902-1911. 